Research Article

\title{
A Multiscale Assessment of Three Satellite Precipitation Products (TRMM, CMORPH, and PERSIANN) in the Three Gorges Reservoir Area in China
}

\author{
Tianyu Zhang, ${ }^{1}$ Yu Yang, ${ }^{2}$ Zeyu Dong, ${ }^{2}$ and Shu Gui ${ }^{2}{ }^{2}$ \\ ${ }^{1}$ Chongqing Climate Center, Chongqing, China \\ ${ }^{2}$ Department of Atmospheric Sciences, Yunnan University, Kunming, China \\ Correspondence should be addressed to Shu Gui; guishu@ynu.edu.cn
}

Received 16 March 2021; Revised 5 May 2021; Accepted 25 May 2021; Published 3 June 2021

Academic Editor: Francisco Molero

Copyright (C) 2021 Tianyu Zhang et al. This is an open access article distributed under the Creative Commons Attribution License, which permits unrestricted use, distribution, and reproduction in any medium, provided the original work is properly cited.

\begin{abstract}
This study evaluated three satellite precipitation products, namely, TRMM, CMORPH, and PERSIANN, over the Three Gorges Reservoir area in China at multiple timescales. The assessment covered the following aspects: the rainfall amount, extreme precipitation, and the rainy-day detection ability. Results indicated that the CMORPH and TRMM estimates of rainfall amount were reasonably good, but the PERSIANN showed a larger bias than the other two satellite products. The data precision of CMORPH was slightly better than TRMM. All three satellite products could reproduce the diurnal cycle of rainfall, i.e., more precipitation in the morning than in the evening. The CMORPH estimates were closest to the gauge observation at 3-hourly and 12-hourly timescales. The data accuracy of CMORPH data was better during the night than in the daytime. At daily timescale, the quality of TRMM data was slightly inferior to the CMORPH, whereas the PERSIANN still differed much from the ground observation. At monthly, seasonally, and yearly timescales, the performance of TRMM was comparable to CMORPH, and both of them were obviously superior to PERSIANN. The rainy-day detection ability of CMORPH and TRMM was much better than PERSIANN. The PERSIANN data tended to overestimate the light rainy days but underestimate the heavy and torrential rainy days. The CMORPH data overestimated mainly the moderate rainy days. The TRMM data overestimated the occurrence frequency of heavy rain during the winter half year (from October to the next March). Both the CMORPH and the TRMM provided good estimates of the regional average rainy days. The data accuracy of CMORPH was slightly better than TRMM, and both were far better than the PERSIANN with respect to the rainfall amount and rainy-day detection. Nevertheless, all satellite estimates showed large biases of extreme precipitation. The CMORPH estimate of the maximum 5-day precipitation was the best of all. Both the CMORPH and TRMM data overestimated the 95th percentile of precipitation, but the PERSIANN data severely underestimated it. The PERSIANN estimates of extreme precipitation amount were the best of all during the daytime, nighttime, and the whole day. The above evaluation results could facilitate the application of satellite rainfall products and provide a reference to precipitation-related studies.
\end{abstract}

\section{Introduction}

Precipitation is one of the most important hydrometeorological variables that directly affect the social economy and people's lives. It exhibits strong spatial-temporal variability and often in a nonuniform distribution. Nevertheless, rainfall obversion is scarce in rural and remote areas, making the estimation of local rainfall a very important yet challenging task [1]. This situation is quite common in the Three
Gorges Reservoir area. The Three Gorges Reservoir area covers the joint region of Sichuan Basin and the middlelower Yangtze River Plain. It has complex terrains that consist of the central Hubei canyon, the eastern Sichuan paralleled ridge-valley, Dabashan Mountain, and the southern Yichuan-Hubei Plateau [2,3]. The large orographic difference between these mountain and plateau areas, as well as the unbalanced economic growth, makes the distribution of weather stations uneven and heterogeneous. This makes 
the application of satellite precipitation measurements far more necessary than in other areas in China.

The recent development of remote sensing and satellite technology offers more choices of satellite precipitation products in a broader range of applications than ever. At present, there are more than 30 inversion methods for the satellite sounding, and more than 10 satellite rainfall estimations (SRE) are available. The representatives of SRE datasets include the Tropical Rainfall Measuring Mission (TRMM) Multisatellite Precipitation Analysis (TMPA) [4], the Climate Prediction Center morphing technique (CMORPH) product [5], the Precipitation Estimation from Remotely Sensed Information Using Artificial Neural Networks (PERSIANN) [6], and the Global Satellite Mapping of Precipitation (GSMaP) [7]. In comparison with other types of precipitation datasets, the satellite precipitation products have a large spatial coverage with a high spatial-temporal resolution, which can effectively compensate for the groundbased weather radar and the rain-gauge observation [8]. The satellite products provide an essential way to measure global precipitation. However, since the satellite measures instantaneous rainfall, the records tend to overestimate or underestimate the actual rainfall amount. Thus, meteorologists often evaluate the satellite products with gauge observation. The accuracy of satellite products varies with the data source and the inversion algorithm. The precision of satellite measurement is also affected by the regional climate types, timescales, and orography [9].

Many satellite products have been assessed and intercompared in different areas around the globe [10-12]. For example, Nashwan et al. [13] reported that the Global Satellite Mapping of Precipitation (GSMaP) was best suitable for the daily rainfall estimation in the arid region of Egypt. Klutse et al. [14] found that the gauge-corrected satellite datasets show similar estimates of summer monsoon rainfall intensity and extreme precipitation over West Africa. Other studies showed that the precipitation estimates exhibited distinct regional-scale patterns among different subregions of the Nile river basin [15] and between coastal and inland areas in Bangladesh [16]. The performance of these satellite products was also evaluated in China. For example, Shen et al. [17] constructed the gauge observation of precipitation on $0.25^{\circ}$ grid spacing and assessed the accuracy of six high-resolution satellite products over China from 2005 to 2007. Cheng et al. [18] assessed the CMORPH and TRMM 3B42 products with hourly precipitation from 2447 gauges in China during 2007-2010. Liao et al. [19] evaluated the accuracy of six precipitation products (TRMM 3B40RT, 3B41RT, 3B42RT, CMORPH, GSMaP, HYDRO) over China on the daily timescale.

The performance of satellite products over complex terrain regions has gained more attention recently due to its increasing importance in rainfall forecast and alleviation of weather-related disasters. For instance, Zhu et al. [20] studied the diurnal rainfall variation over the contiguous United States and found significant discrepancies in the spatial clustering features between the TRMM data and the gauge observations. Chen et al. [21] reported that TRMM was slightly better than CMORPH in capturing the rainfall diurnal cycle at the South China coast, but CMORPH revealed more local details than TRMM. Guo et al. [22] suggested that the diurnal cycle of rainfall in Tibet was largely dependent on topography and landscape. Other studies were conducted in a similar manner to evaluate the satellite products over Tibetan Plateau [23], Yellow River Valley and high-latitude and low-latitude basins in China [24-27], Zhouqu in Northwest China [28], Qinling-Dabashan Mountains [29], and Shanghai [30]. In general, most of the abovementioned studies have been made to evaluate the precipitation on a daily timescale and above.

At present, the applicability of satellite products in the Three Gorges Reservoir area has yet to be studied thoroughly. Li et al. [31] suggested that most satellite products, including TRMM3B42-V7, TRMM3B42-RT, PERSIANN, and CMORPH, still suffered from biases to a certain degree over the Yangtze River Basin. The TRMM-based precipitation products gained much attention in previous studies over Sichuan and Chongqing areas [32-34], Hubei Province [35], the Tibetan Plateau [36], and the Three Gorges Reservoir area [37]. Nevertheless, these studies mainly focused on the daily timescale and above. The precision of satellite data varies with the climate types, orography, observation timescales, and inversion algorithms. On the other hand, the unique topographic distribution of the Three Gorges Reservoir area results in large differences in orographic lifting and remarkably different rainfall patterns within the region. The Dabashan Mountain and its extension to the Shennongjia mountain in the north of Yangtze River act together with the Wushan Mountain in the south of Yangtze River to shield the cold air from Siberia, making the Three Gorges Reservoir area a warm and humid place. The entire reservoir area is dominated by the humid subtropical climate. The climate of the Three Gorges Reservoir area is characterized by moderate rainfall, warm winter but hot summer, rainfall with hot temperatures in the same season. The average temperature of the Three Gorges Reservoir area is $17 \sim 19^{\circ} \mathrm{C}$, and the daily range and annual range of temperature are small. The annual precipitation of the reservoir area is 1000 $\sim 1300 \mathrm{~mm}$, spatially characterized by a zonal tripolar pattern with more rainfall at both ends but less rainfall over the central area of the riverside valley. The rainfall pattern over the Three Gorges Reservoir area is relatively complex, but few studies have focused on this area to reveal the regional variation characteristics of precipitation. Thus, there is an urgent need to investigate the reliability of satellite products.

This study is intended to fill this gap by evaluating three high-resolution satellite products (TRMM, CMORPH, and PERSIANN) with gauge-observed precipitation over the Three Gorges Reservoir area from subdaily to yearly timescales. The consistency and difference among the satellite products in detecting extreme precipitation and rainy days in complex terrains are also discussed. The remainder of this paper is organized as follows. In Section 2, the source of observation, the reanalysis data, and the methodology are introduced. In Section 3, the satellite rainfall measurements 
from subdaily to yearly timescales are intercompared and evaluated with meteorological observation. In Section 4, the detection capability of rainy days is evaluated for each satellite product. In Section 5, the satellite measurements of extreme precipitation are evaluated. Finally, a summary and discussion are given in Section 6.

\section{Data and Methods}

2.1. Data. The precipitation observation in the Three Gorges Reservoir area was derived from 35 national weather stations with elevation from $177.9 \mathrm{~m}$ to $786.9 \mathrm{~m}$ above sea level. There were 12 stations in Hubei Province and 23 stations in Chongqing city (Figure 1). The hourly rainfall records were preprocessed into the accumulated precipitation of different timescales (i.e., 3 hours, 12 hours, daily, monthly, seasonally, and yearly). The high-resolution satellite data used in this study is listed in Table 1. These satellite products were the TRMM 3B42 version 7 (TRMM 3B42_V7) [4], the PERSIANN version 1.1 (PERSIANN-CDR) [6], and the CMORPH version 1 (CMORPH CRT) [5]. The satellite data was preprocessed on the same grid resolution of $0.25^{\circ} \times 0.25^{\circ}$ and the same time resolution every 3 hours. Given the different time spans of these products, the longest time period available for all satellite data is used for evaluation. Thus, all data spanned from January 1, 2001, to December 31, 2016 (a total of 16 years).

2.2. Methods. The satellite precipitation products were evaluated for the estimated rainfall amount, the classification of rainy and rainless cases, and the distribution and persistency of extreme precipitation. Six statistical matrices were used for the rainfall amount evaluation, namely, correlation coefficient, root-mean-square error, bias, KlingGupta Efficiency index, Theil's U coefficient, and Probability Distribution Function. Three categorical indices were used to appraise the rainy and rainless cases, namely, hit bias, probability of detection, and false alarm rate. Three statistical indices were used to evaluate the extreme precipitation, namely, the maximum 5-day precipitation, the extreme precipitation amount, and the persistent rainy days. The definition of these indices, except the commonly known ones, is provided herein.

2.2.1. RMSE. The root-mean-square error (RMSE) is calculated as the square root of the average squared difference between the satellite estimates and the observed value:

$$
\mathrm{RMSE}=\sqrt{\frac{\left[\sum_{i=1}^{n}\left(S_{i}-G_{i}\right)^{2}\right]}{n}},
$$

where $S_{i}$ denotes the satellite rainfall estimates, $G_{i}$ represents the observed precipitation, and $n$ denotes the number of time points for evaluation.
2.2.2. Bias. The bias metric directly reveals the systematic errors of satellite estimates and the extent of these errors in reference to the observation:

$$
\text { bias }=\sum_{i=1}^{n} \frac{\left(S_{i}-G_{i}\right)}{\sum_{i=1}^{n} G_{i}} \times 100 \%,
$$

where $S_{i}, G_{i}$, and $n$ denotes the same quantities as in equation (1).

\subsubsection{Kling-Gupta Efficiency. The Kling-Gupta efficiency} (KGE) is defined as

$$
\mathrm{KGE}=1-\sqrt{(r-1)^{2}+(\beta-1)^{2}+(\gamma-1)^{2}},
$$

where the correlation component $r$ was Pearson's correlation coefficient, the bias component $\beta=\mu_{s} / \mu_{o}$ was the ratio between the estimated mean $\left(\mu_{s}\right)$ and observed mean $\left(\mu_{o}\right)$, and the variability component $\gamma=\left(\sigma_{s} / \mu_{s}\right) /\left(\sigma_{o} / \mu_{o}\right)$ denoted the ratio between the estimated variation coefficients $\left(\sigma_{s} / \mu_{s}\right)$ and the observed counterpart $\left(\sigma_{o} / \mu_{o}\right)\left(\sigma_{o}\right.$ and $\sigma_{s}$ denoted the standard deviation of observation and satellite estimates) $[38,39]$. The perfect value for the KGE score is 1 .

\subsubsection{Theil's $U$ Coefficient. Theil's $U$ score is defined as}

$$
U=\sqrt{\frac{\sum_{i=1}^{n}\left(M_{i}-O_{i}\right)^{2}}{\sum_{i=1}^{n} M_{i}^{2}}},
$$

where $M_{i}$ presents the satellite data of the $i$ th sample, $O_{i}$ is the corresponding observation, and $n$ is the total number of samples. The perfect value for Theil's $U$ coefficient is 0 [40].

2.2.5. Hit Bias. The hit bias is a classification index that measures the congruency between the satellite estimates and the observation. This index is calculated as the number of rainy days of satellite data divided by the number of observed rainy days.

$$
\mathrm{HB}=\frac{\mathrm{NA}+\mathrm{NB}}{\mathrm{NA}+\mathrm{NC}}
$$

where $\mathrm{HB}$ is the hit bias, NA is the number of rainy days in both the observation and the satellite estimates, NB is the number of rainy days only in the satellite estimates, and the $\mathrm{NC}$ is the number of rainy days only in the observation. The ideal value for $\mathrm{HB}$ is 1 .

2.2.6. Probability of Detection. The probability of detection (POD) reflects the accuracy of satellite estimates. It is calculated as the ratio between the number of rainy days in both the observation and the satellite estimates and the total number of rainy days in the observation. 


$$
\mathrm{POD}=\frac{\mathrm{NA}}{\mathrm{NA}+\mathrm{NC}},
$$

where the NA and NC have the same meaning as in equation (5). The ideal value for POD is 1 .

2.2.7. False Alarm Rate. The false alarm rate (FAR) reflects the false rate in the satellite detection of rainfall. It is calculated as the ratio between the number of rainy days only in the satellite estimates and the total number of rainy days in the satellite estimates.

$$
\mathrm{FAR}=\frac{\mathrm{NB}}{\mathrm{NA}+\mathrm{NB}},
$$

where NA and NB have the same meaning as in equation (5). The ideal value for FAR is 0 .

\subsubsection{Metrics for Rainy Days and Extreme Precipitation}

(a) Effective rainy days: the rainfall threshold for each rainy day was set to $1 \mathrm{~mm} /$ day $[41,42]$.

(b) Classification of rainy days for different precipitation magnitudes: according to the operation regulation of the China Meteorological Administration, the rainfall intensity was classified as follows:

$$
\begin{aligned}
& \text { Light rain: } 0.1 \sim 9.9 \mathrm{~mm} / \text { day } \\
& \text { Moderate rain: } 10.0 \sim 24.9 \mathrm{~mm} / \text { day } \\
& \text { Heavy rain: } 25.0 \sim 49.9 \mathrm{~mm} / \text { day } \\
& \text { Rainstorm and above: } \geq 50 \mathrm{~mm} / \text { day }
\end{aligned}
$$

(c) The 3 indices in Table 2 were adopted from the 27 indices of extreme weather events proposed by the World Meteorological Organization (WMO) $[43,44]$.

2.2.9. Kriging Interpolation. The Kriging interpolation method is a popular geostatistical technique in groundwater modeling and spatial mapping. It uses a variogram to determine the spatial variation on the surface and minimize the prediction error at unmeasured locations. In comparison to other interpolation methods such as the inverse distance weighted method and spline interpolation, the Kriging method maximizes the utilization of the observed spatial information and thus makes a more precise estimate at uncharted locations [45, 46]. Given the above reason, we adopted the Kriging method to interpolate the satellite data onto the location of each meteorological station and then accumulated the precipitation amount at 3-hourly, 12hourly, daily, monthly, seasonally, and yearly timescales.

\section{Results and Discussion}

3.1. Multitimescale Assessment of Precipitation. The precipitation climatology consisted of two local maxima, one over the south and the other over the north (Figure 2). This spatial pattern was consistent with previous studies with respect to the location of maximum and minimum centers [37, 47]. Both the TRMM and the CMORPH estimates were close to the observation regarding the location and magnitude of the rainfall maximum and minimum. The PERSIANN estimates of rainfall amount were smaller than the observation. In addition, the spatial pattern of PERSIANN rainfall differed from the observation, with an obvious shift of the maximum center and its spatial coverage.

3.1.1. 3-Hourly Timescale. The gauge-observed precipitation displayed large diurnal variabilities over the southern reservoir area, with the maximum standard deviation over $6 \mathrm{~mm} /$ day (Figure 2(e)). The diurnal variabilities were a bit smaller in the northern and western parts of the area. Both CMORPH and TRMM could reproduce this spatial pattern to a large extent (Figures 2(f) and 2(g)). Nevertheless, the TRMM data overestimated the standard deviation for approximately $1 \mathrm{~mm} /$ day. The PERSIANN underestimated the diurnal variability over the entire reservoir area (Figure 2(h)).

The mean precipitation rate was heavier during the first 12 hours of a day $(0-12)$ than the rest (12-24) (Figure 3$)$. This implied a "more in the morning but less in the evening" feature of the rainfall diurnal cycle. The diurnal variation of precipitation could be related to the mountain-plains solenoid (MPS) circulation $[20,48]$. The rainfall peak was most likely to appear around the $3^{\text {rd }}$ - to $9^{\text {th }}$-hour interval. The mean standard deviations of observed precipitation ranged from $3.8 \mathrm{~mm} /$ day to $5.6 \mathrm{~mm} /$ day during the research period. All three satellite estimates presented a rainfall diurnal cycle similar to the observation. The CMORPH best reproduced the observed variation pattern with respect to the rainfall amount and its standard deviation. The TRMM presented a similar diurnal variation, but it tended to overestimate the diurnal variability for about $1 \mathrm{~mm} /$ day. The PERSIANN obviously underestimated the overall rainfall amount and its standard deviation (more than $2 \mathrm{~mm}$ /day in most years). In general, the CMORPH estimate of the rainfall diurnal cycle was the best, followed by TRMM and then PERSIANN.

The relative bias of each satellite dataset is given in Figure 4. In spring, the CMORPH showed the smallest bias, fluctuating around 0 throughout the day (Figure 4(a)). The TRMM estimate was positively biased during the first 12 hours of a day, but negatively biased for the rest of a day. The positive bias reached its peak during the $3^{\text {rd }}-6^{\text {th }}$ hour period, whereas the negative bias reached its peak during the $12^{\text {th }}-18^{\text {th }}$ hour period. Although the TRMM estimate was more biased than the CMORPH, it was still better than the PERSIANN. In comparison to the observation, the PERSIANN underestimated the rainfall amount throughout the whole day. All satellite biases showed a decreasing trend in the morning and an increasing trend in the evening. In summer, the CMORPH bias was still the smallest among all satellite datasets during the first 15 hours of a day (Figure 4(b)). The CMORPH bias reached its peak during the $12^{\text {th }}-15^{\text {th }}$ hour period, and it remained positive for the rest of a day. The TRMM bias consisted of two positive peaks around the $3^{\text {rd }}-6^{\text {th }}$ hours and $12^{\text {th }}-15^{\text {th }}$ hours. The TRMM bias was larger than the CMORPH until the $18^{\text {th }}$ hour, when the two satellite estimates had a similar bias rate. Since then, 


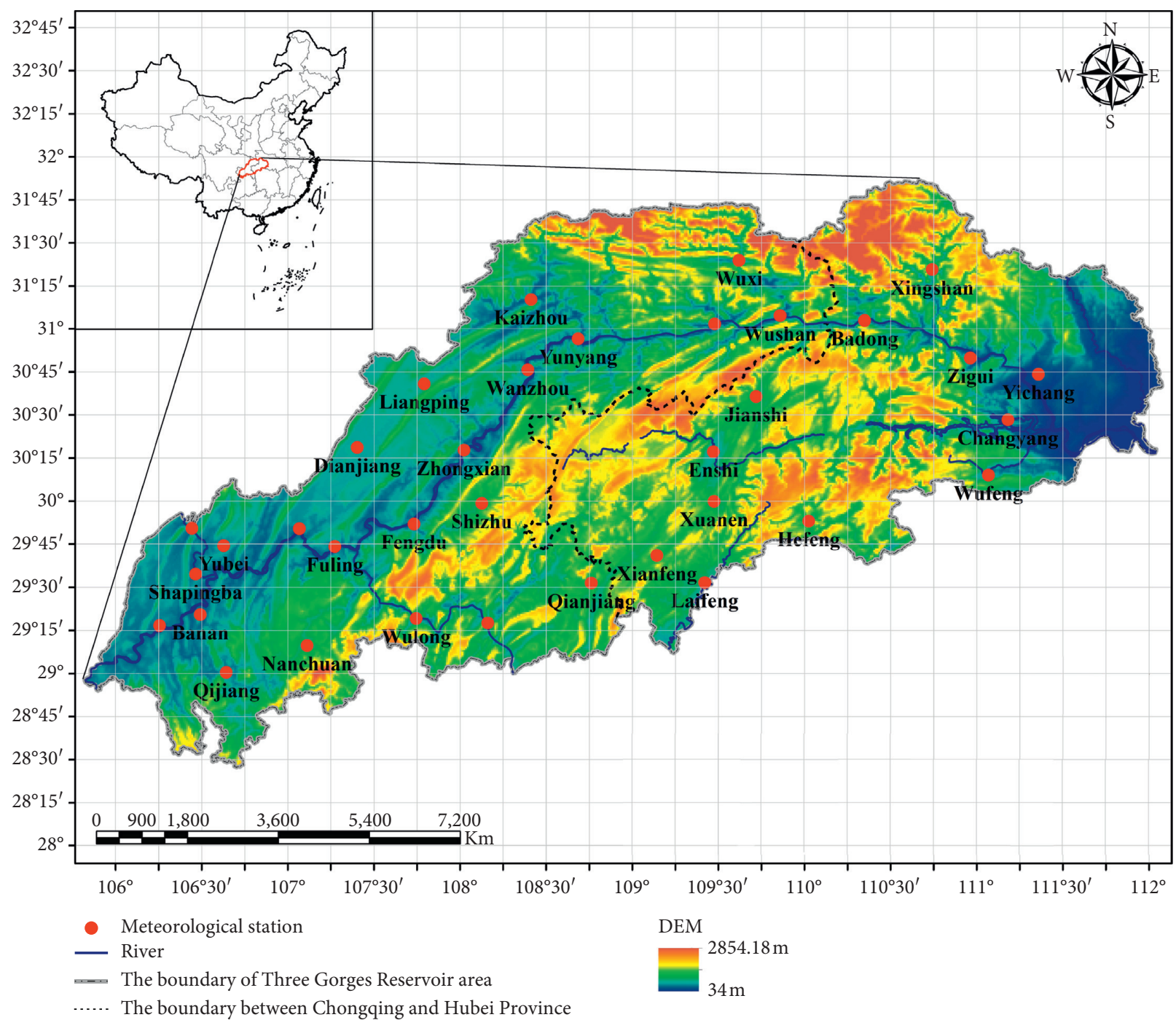

FIgURE 1: Distribution of national meteorological stations in the Three Gorges Reservoir area.

TABLE 1: Summary of the three satellite products.

\begin{tabular}{llccc}
\hline Satellite products & Source & Inversion algorithm & Time resolution (h) & Spatial resolution \\
\hline TRMM 3B42_V7 & NASA & TMPA & 3 & $0.25^{\circ} \times 0.25^{\circ}$ \\
PERSIANN-CDR & NOAA & CPC cloud moving vector morphing & 3 & $0.25^{\circ} \times 0.25^{\circ}$ \\
CMORPH V1.0 & NOAA & ANN & 3 & $0.25^{\circ} \times 0.25^{\circ}$ \\
\hline
\end{tabular}

TABLE 2: The indices for extreme precipitation.

\begin{tabular}{lccc}
\hline Index & Abbreviation & Definition & Units \\
$\begin{array}{l}\text { The maximum 5-day } \\
\text { precipitation }\end{array}$ & RX5day & The maximum accumulated rainfall for consecutive 5 days in a year & mm \\
$\begin{array}{l}\text { The extreme precipitation } \\
\text { amount }\end{array}$ & R95 & The precipitation amount above the 95th percentile of daily precipitation in a & mm \\
Persistent rainy days & CWD & The longest period with more than 1 mm rainfall per day & day \\
\hline
\end{tabular}

the TRMM data had been negatively biased. The PERSIANN estimate was still remarkably lower than the observation throughout the day. In autumn, the CMORPH estimate was still the best, with the bias range within 20\% (Figure 4(c)). The TRMM bias was larger than the CMORPH during the $15^{\text {th }}-21^{\text {st }}$ hours. The PERSIANN estimate was remarkably lower than the observation for about $60 \%$. In winter, both the CMORPH and the 


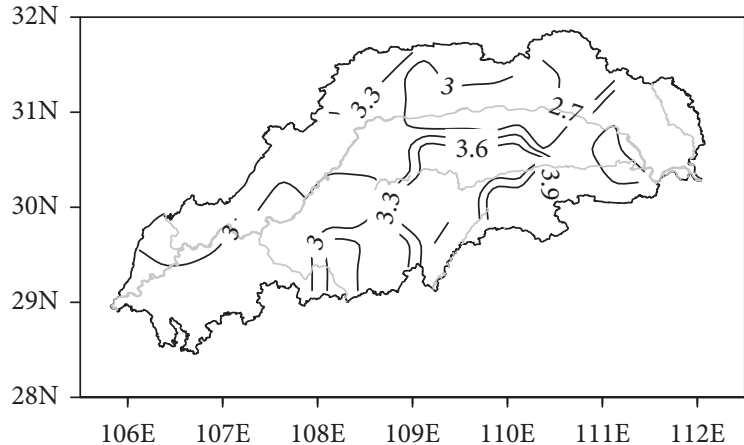

(a)

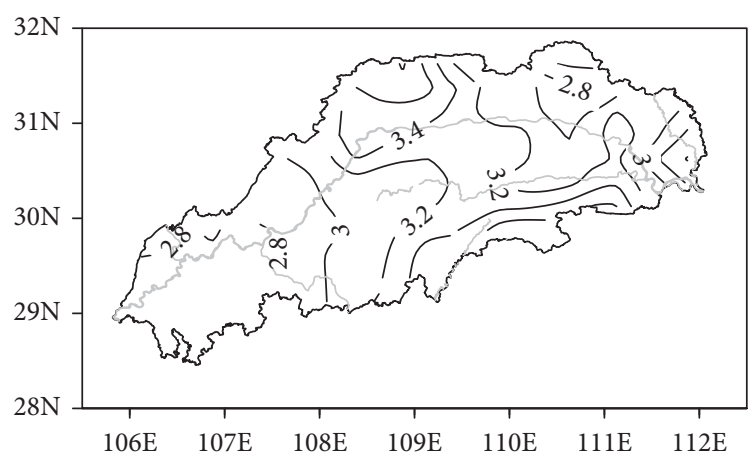

(c)

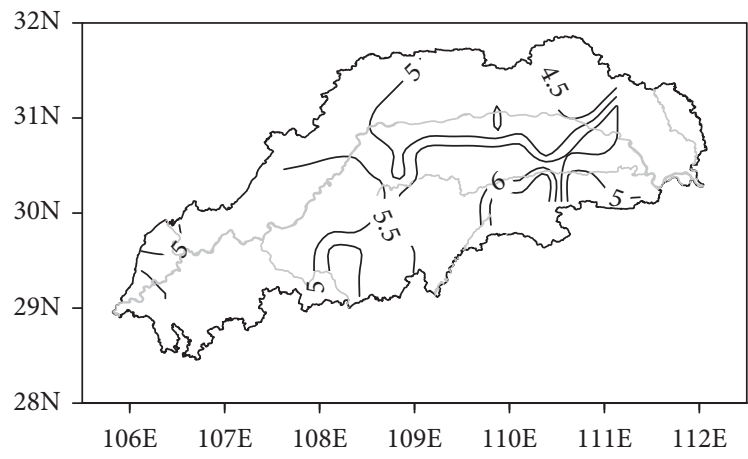

(e)

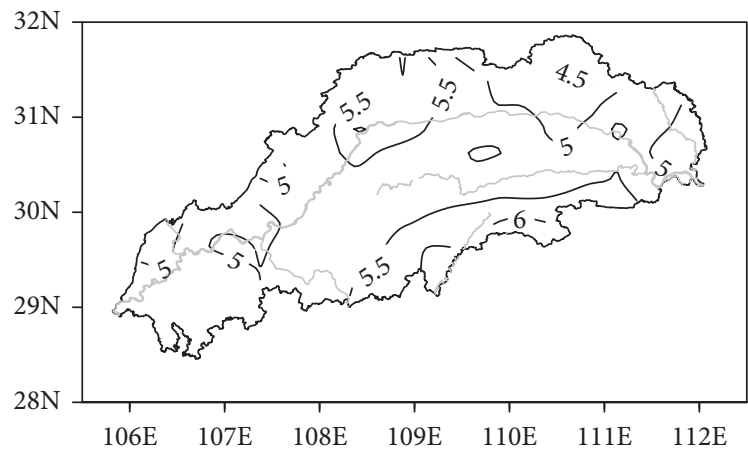

(g)

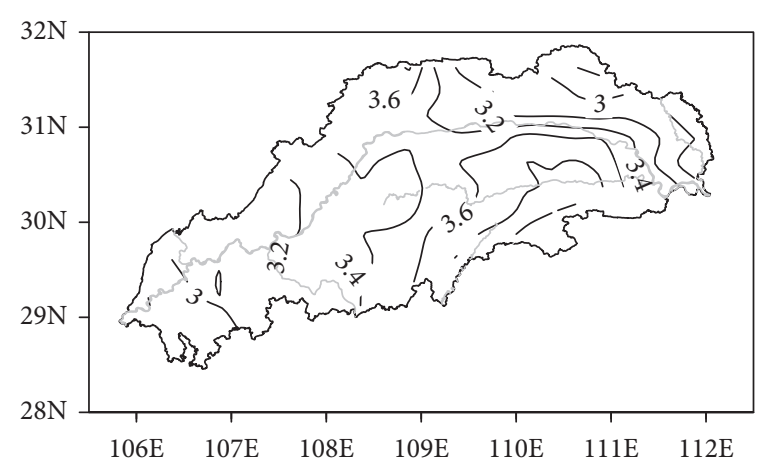

(b)

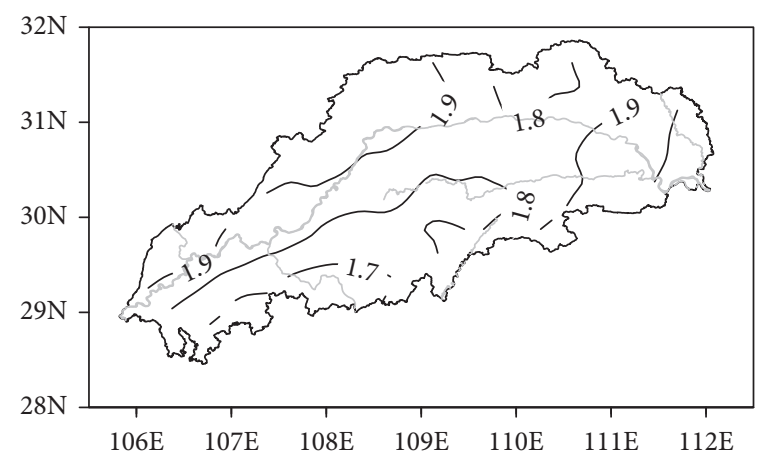

(d)

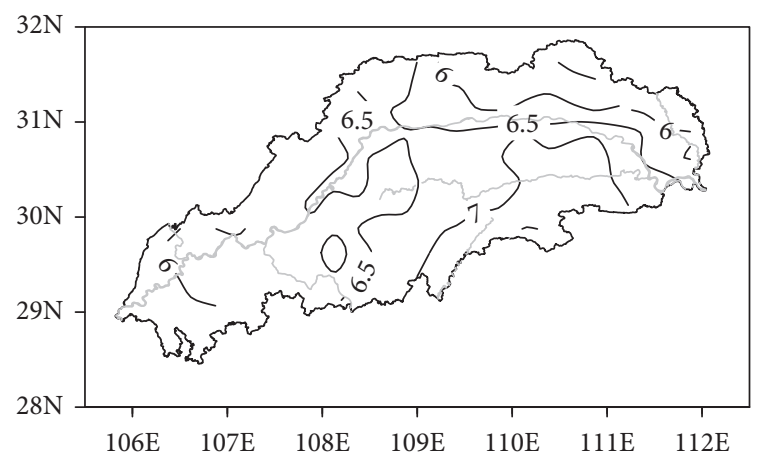

(f)

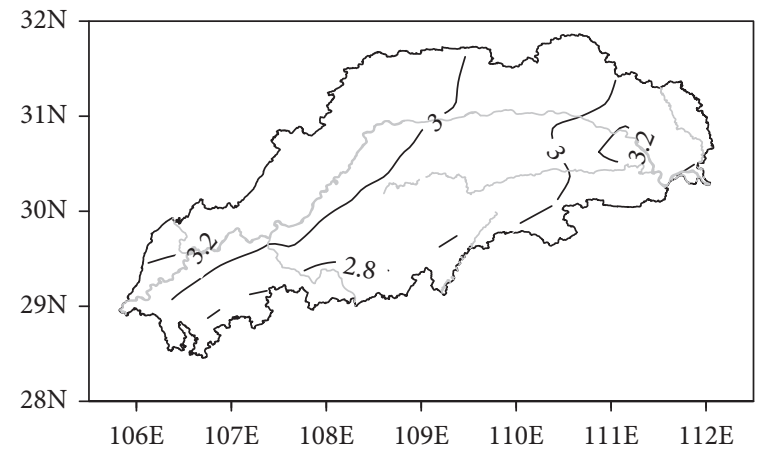

(h)

FIGURE 2: The spatial distribution of annual mean precipitation (contour units: $\mathrm{mm} / \mathrm{day}$ ) and the mean standard deviation of 3-hourly precipitation rate (contour units: mm/day) for (a, e) gauge observation, (b, f) TRMM, (c, g) CMORPH, and (d, h) PERSIANN. 


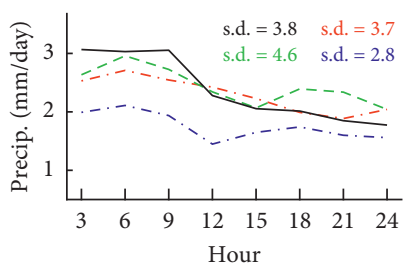

..- CMORPH -.- TRMM ... PERSIANN — Obs.

(a)

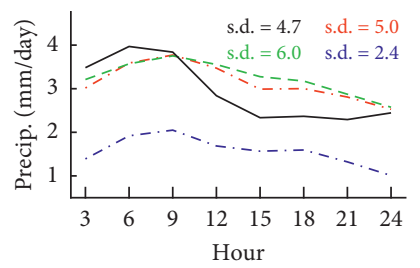

... CMORPH -.- TRMM ... PERSIANN — Obs.

(e)
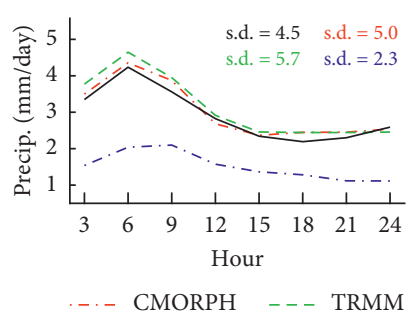

... PERSIANN — Obs.

(i)

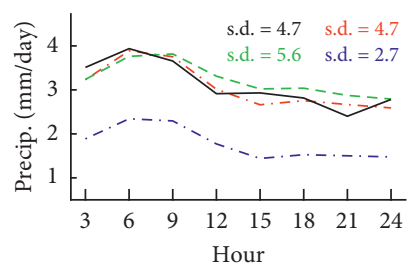

-.. CMORPH _. TRMM

... PERSIANN — Obs.

(m)

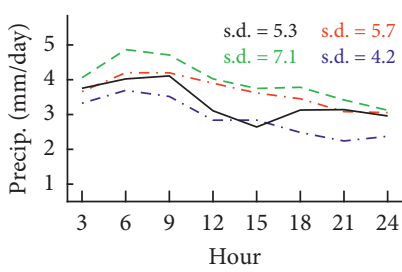

... CMORPH - -- TRMM ... PERSIANN — Obs.

(b)

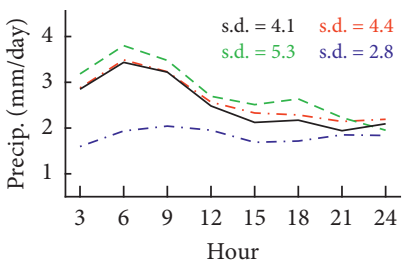

... CMORPH -.- TRMM ... PERSIANN — Obs.

(f)
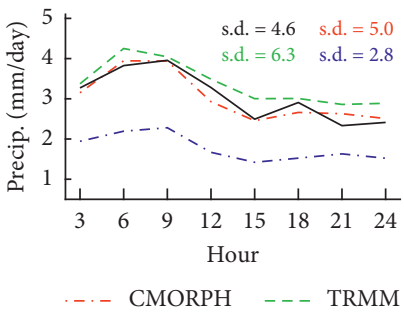

-.. PERSIANN — Obs.

(j)
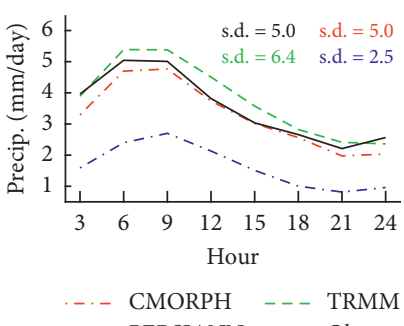

... PERSIANN — Obs.

(n)

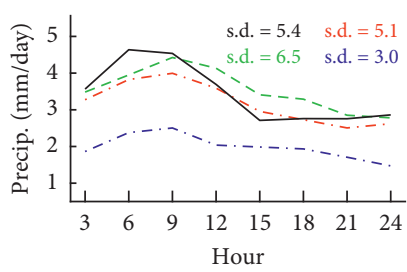

...- CMORPH -.- TRMM ... PERSIANN — Obs.

(c)

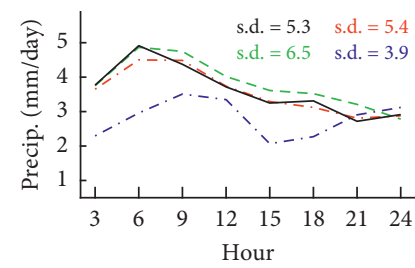

-.. CMORPH -.- TRMM ... PERSIANN — Obs.

(g)
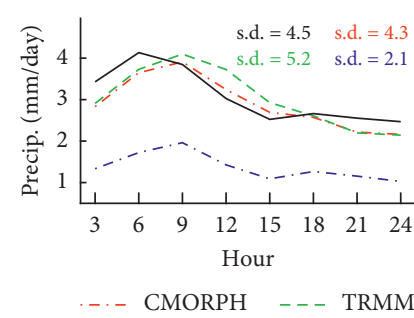

... PERSIANN — Obs.

(k)

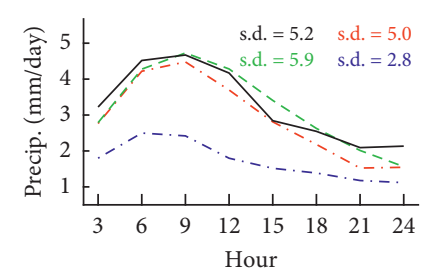

... CMORPH _.- TRMM

(o)

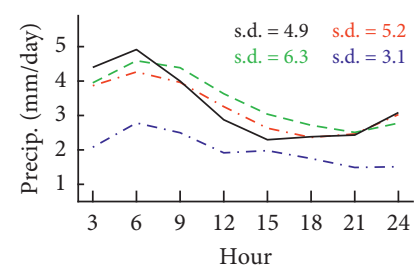

...- CMORPH -.- TRMM ...- PERSIANN — Obs.

(d)

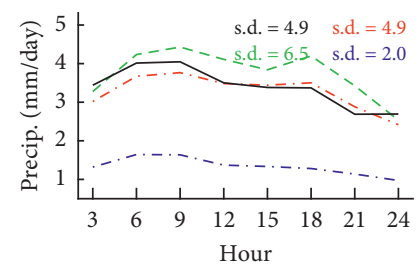

...- CMORPH -.- TRMM

... PERSIANN — Obs.

(h)

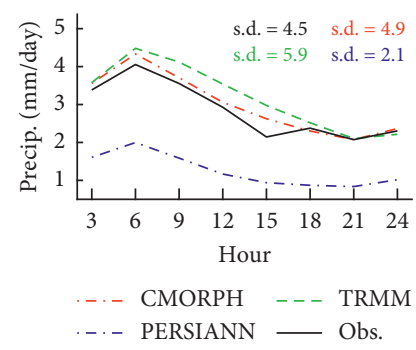

(1)

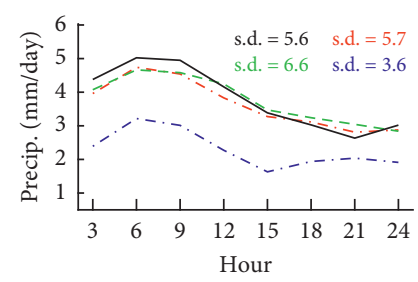

...- CMORPH - - TRMM

-.. PERSIANN — Obs.

(p)

FIgURE 3: The annual mean 3-hourly precipitation rate over the Three Gorges Reservoir area from the observation and the satellite estimates during the period 2001-2016 (units: mm/hour). The mean standard deviations (s.d.) of diurnal anomalies were annotated on each subplot.

PERSIANN underestimated the rainfall amount for an average of $25 \%$, whereas the TRMM conspicuously overestimated the precipitation during the $3^{\text {rd }}-6^{\text {th }}$ hours (Figure 4(d)).

The bias distribution in each season was shown in the box plot (Figure 5). All three satellite datasets showed a broad range of biases and diverse distribution of the median in four seasons. In spring, the CMORPH bias was mainly positive with the median value over $100 \%$ (Figure $5(\mathrm{a})$ ). This bias rate was higher than those of the TRMM and PERSIANN, suggesting that the CMORPH suffered from an overall overestimation of the spring precipitation. The
TRMM bias covered a broader range than the CMORPH, suggesting a higher discreteness of the estimate errors. The median of TRMM bias was around $80 \%$, less than that of CMORPH. It implied that the TRMM still suffered from an overestimation of spring rainfall but to a lesser degree compared to the CMORPH. The PERSIANN bias was even more spread out than the TRMM, but its median was close to 0 . Since the rainfall amount was generally underestimated in the PERSIANN, this small median suggested that the underestimation of rainfall was offset by the overestimation of rainfall in some areas with small rainfall amounts. In summer, the bias distribution and the median value of 


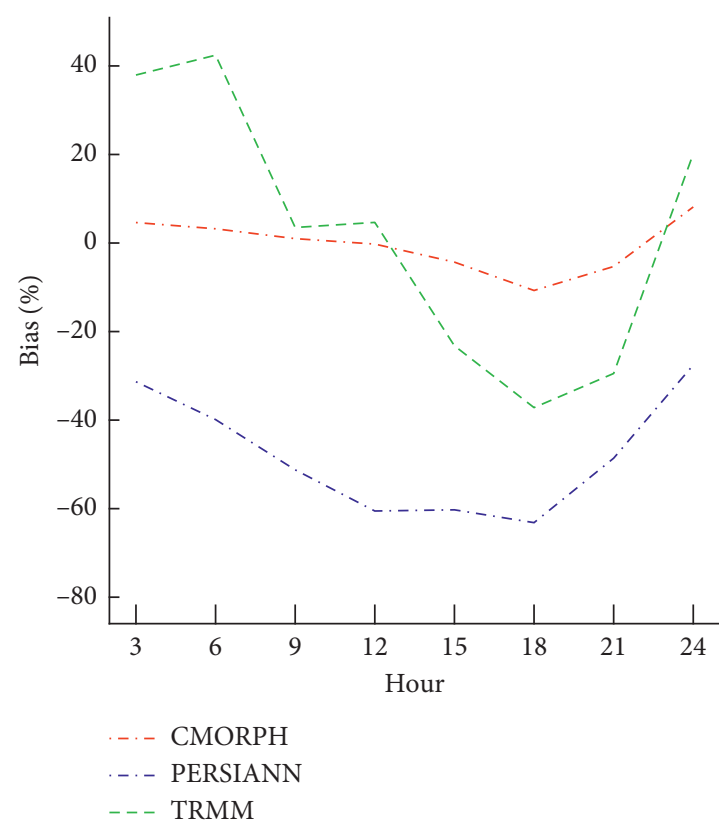

(a)

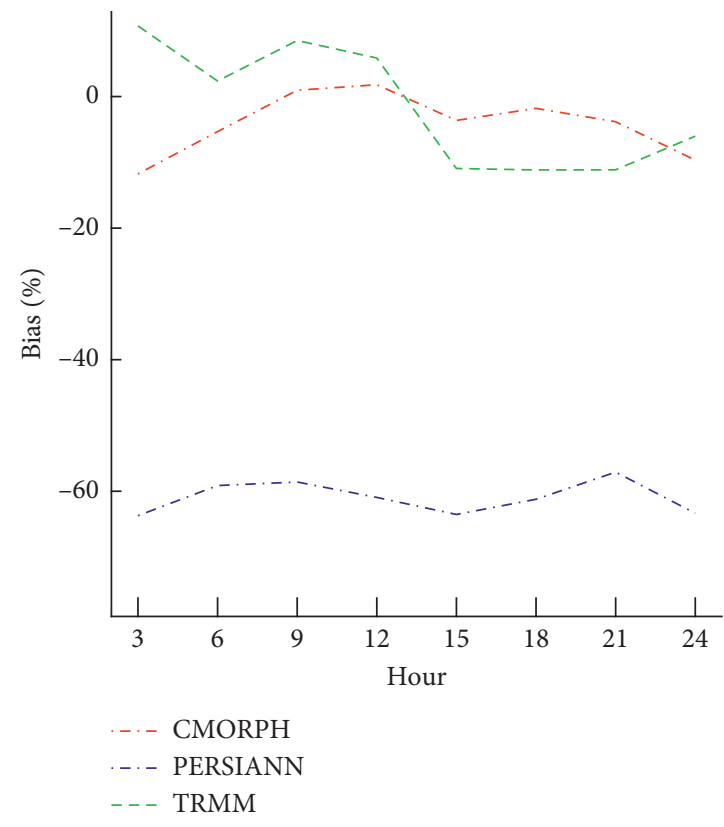

(c)

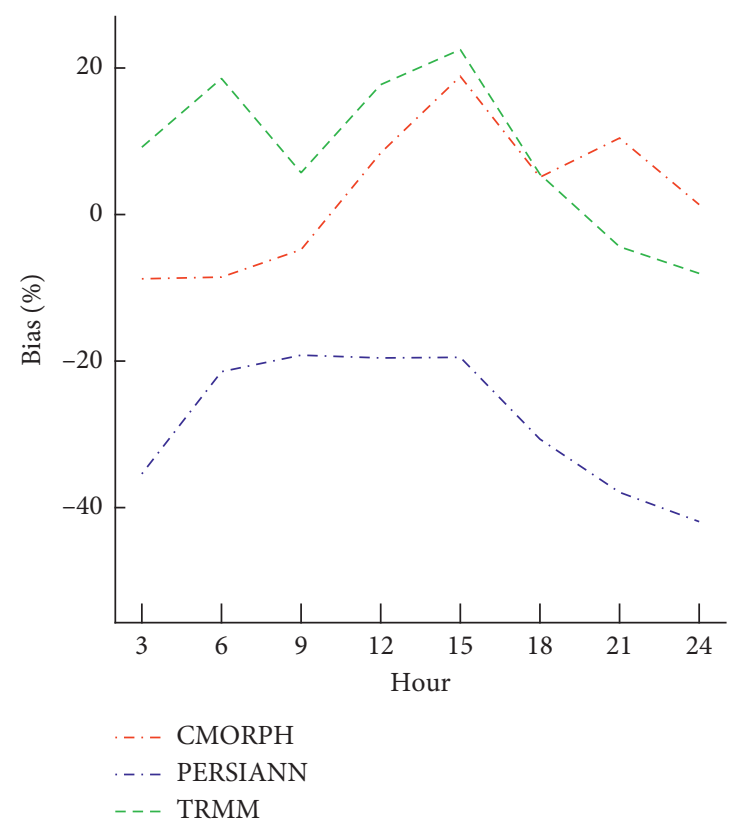

(b)

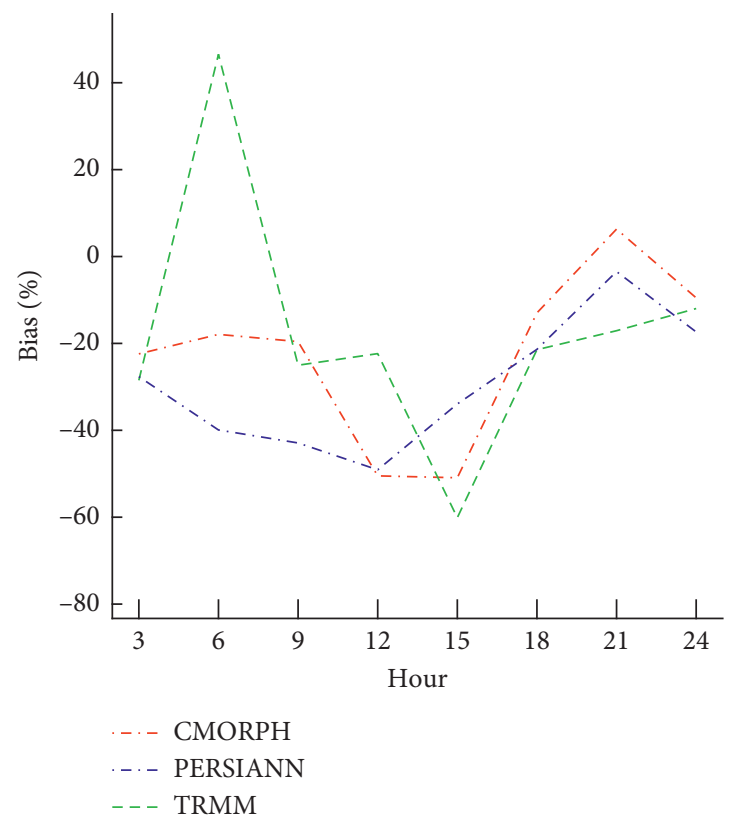

(d)

Figure 4: The average bias rate of each satellite dataset over the Three Gorges Reservoir area in (a) spring, (b) summer, (c) autumn, and (d) winter.

CMORPH and TRMM resembled each other (Figure 5(b)). Both of them overestimated the precipitation in most parts of the Three Gorges Reservoir area. The PERSIANN still showed the largest percentile range with the median value close to 0 . In autumn, all three satellite estimates exhibited a more diverse bias distribution than in summer (Figure 5(c)). The median of TRMM bias was closest to 0 , suggesting a balanced distribution of positive and negative biases over the research area. Likewise, the median of CMORPH bias was about $10 \%$. The PERSIANN bias had the lowest median of all satellite datasets, which implied a severe underestimation of rainfall amount. In winter, all satellite biases exhibited the largest range throughout the year (Figure 5(d)). The bias median of TRMM and PERSIANN resembled their counterpart in autumn, but the bias median of CMORPH was much larger than in autumn (close to 100\%). This indicated that the TRMM and PERSIANN were still inclined to underestimate the rainfall amount, whereas the CMORPH suffered from an overall overestimation of rainfall amount in winter.

In all four seasons, the bias range was the smallest in summer but the largest in winter. Nevertheless, the Three 


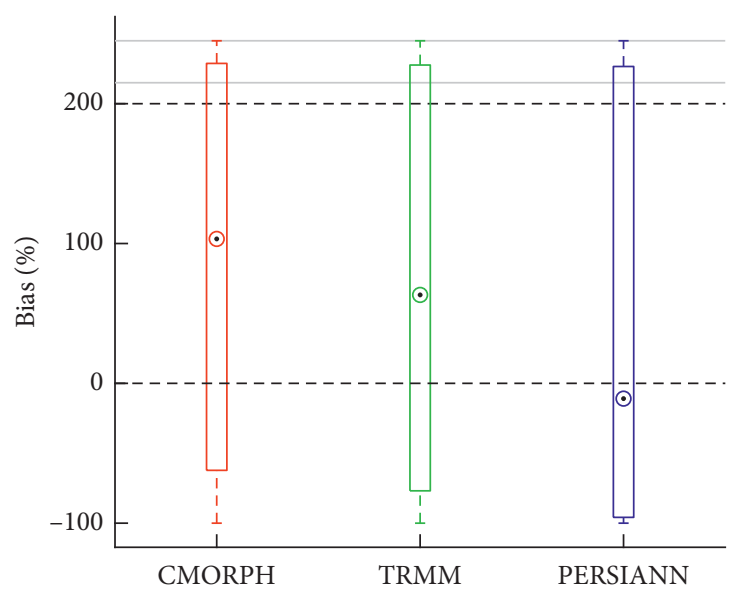

(a)

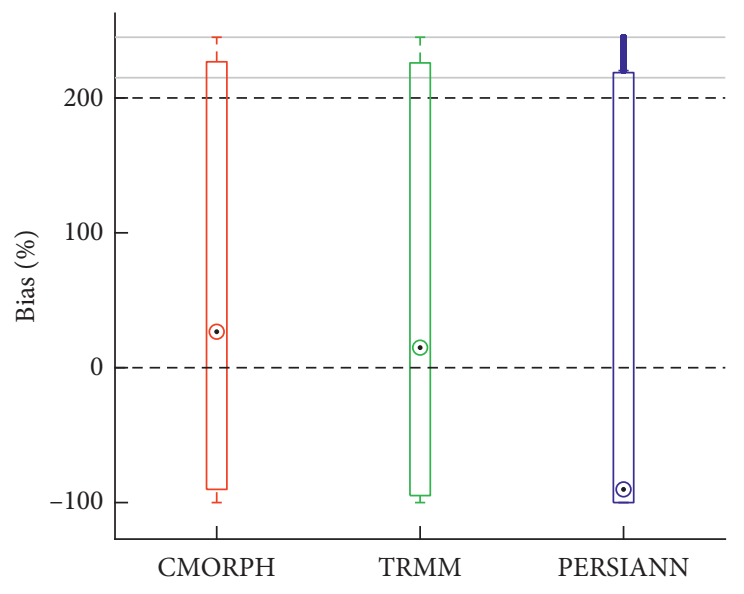

(c)

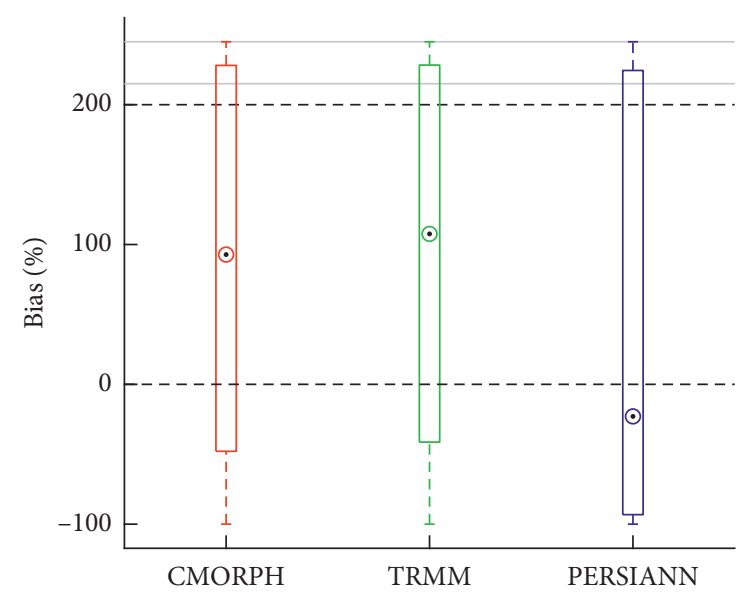

(b)

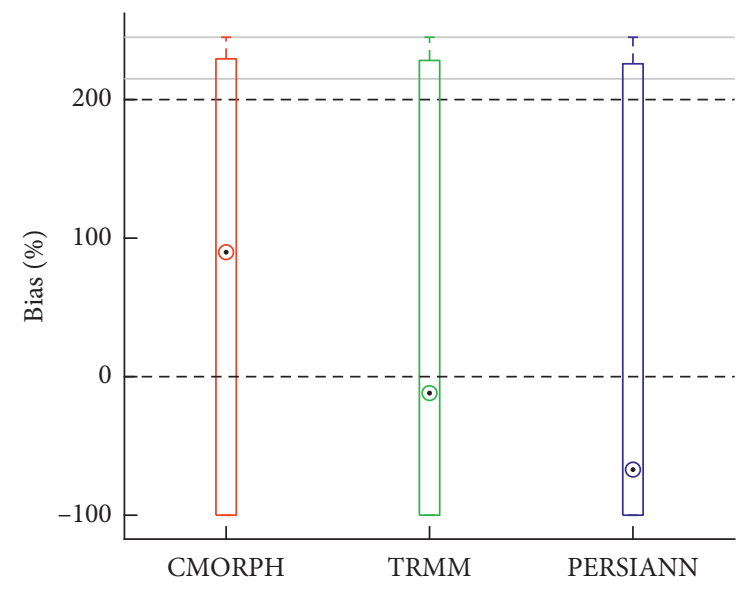

(d)

FIGURE 5: The bias distribution of each satellite dataset over the Three Gorges Reservoir area in (a) spring, (b) summer, (c) autumn, and (d) winter. The upper and lower boundary of each box represented the $25^{\text {th }}$ and $75^{\text {th }}$ percentiles of the samples, the circle with a black dot inside denoted the median in each bar, and the bias rate was confined within $300 \%$ for clarity.

Gorges Reservoir area experienced most of its rainfall in summer and the winter was its dry season. Thus, the scarcer precipitation came with higher discreteness of estimate errors. Among all satellite datasets, the PERSIANN estimates had the highest discreteness of errors. The biases of TRMM and CMORPH were distributed within a similar range. Given the large positive median of CMORPH, this satellite dataset was inclined to overestimate the rainfall. Likewise, the TRMM also tended to overestimate the precipitation in spring and summer. Conversely, the PERSIANN tended to underestimate the rainfall in autumn and winter even more than in spring and summer.

3.1.2. 12-Hourly Timescale. The 12-hourly precipitation could reflect the accuracy of satellite estimates during the daytime and the nighttime. At daytime, the CMORPH estimate was closest to observation among all satellite datasets (Figure 6). The precipitation amount between $4 \mathrm{~mm}$ and $32 \mathrm{~mm}$ was distributed most frequently around the $1: 1$ line. The correlation coefficient between the CMORPH and the gauge observation was 0.81 , the root-mean-square error was
2.90, and the average bias rate was $2.07 \%$ (Table 3 ). The distribution of TRMM estimates was similar to the CMORPH, but the bias between $4 \mathrm{~mm}$ and $16 \mathrm{~mm}$ was larger than that of the CMORPH. The correlation coefficient between the TRMM estimates and the rainfall observation was 0.81 , the root-mean-square error was 3.04 , and the bias rate was $6.79 \%$. In comparison to the CMORPH, the accuracy of TRMM was slightly inferior. The PERSIANN estimates missed a high-frequency appearance around the 1:1 line. The correlation coefficient between the PERSIANN estimates and the rainfall observation was 0.54 , the root-meansquare error was 4.66 , and the bias rate was $-35.20 \%$. Judging from these three metrics, the CMORPH estimate was the best of all.

The distribution of nocturnal precipitation was similar to that at daytime (Figure 7). The CMORPH still presented the highest frequency appearance around the $1: 1$ line between $4 \mathrm{~mm}$ and $32 \mathrm{~mm}$. The evaluation metrics of the CMORPH were as follows: correlation coefficient of 0.82 , root-meansquare error of 3.55 , and the bias rate of $-0.34 \%$ (Table 4 ). In comparison to the daytime precipitation, the correlation coefficient of nocturnal precipitation was higher and the bias 


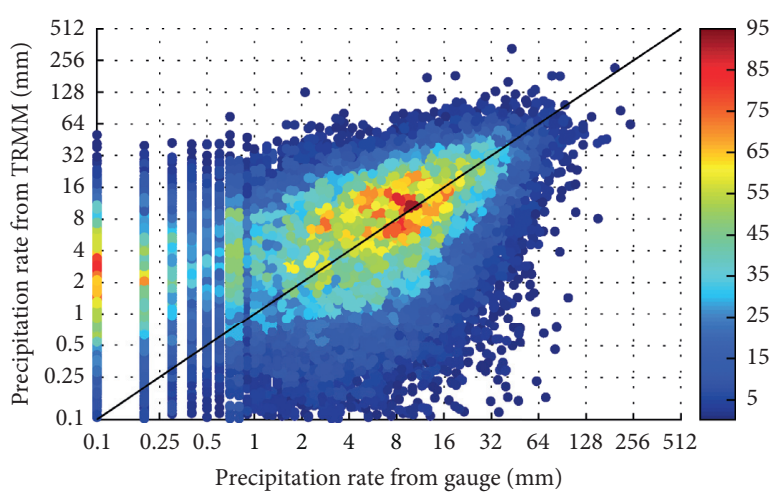

(a)

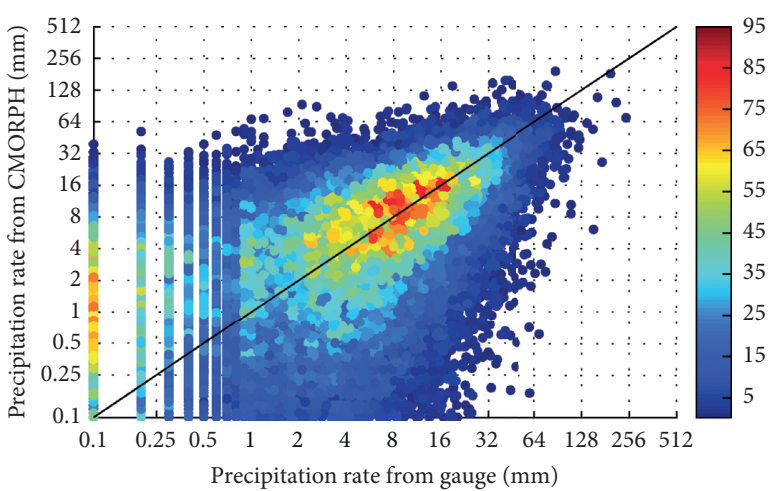

(b)

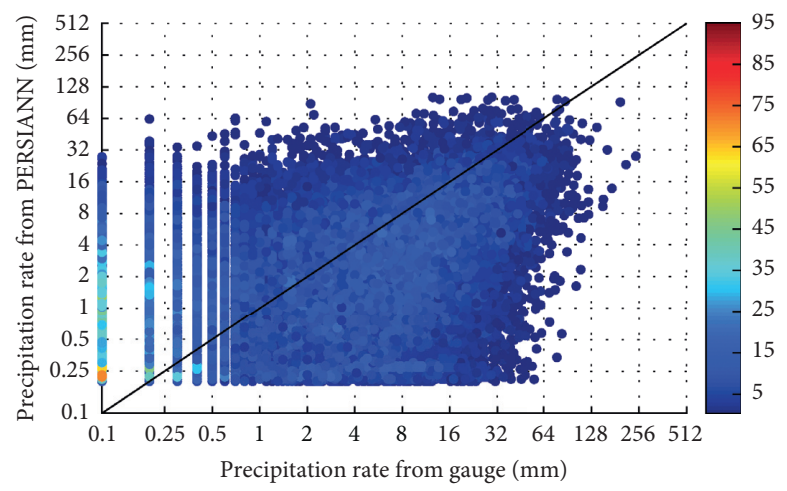

(c)

FIGURE 6: Scatter plot of the observed precipitation and (a) the TRMM, (b) the CMORPH, and (c) the PERSIANN estimates over the Three Gorges Reservoir area in the daytime. Since the minimum scale of a rainfall gauge was $0.1 \mathrm{~mm}$, the observed precipitation less than $1 \mathrm{~mm}$ was displayed as discrete points on the scatter plot.

rate was lower, but the root-mean-square error increased a little bit. The TRMM estimates at nighttime appeared less frequently around the $1: 1$ line compared to the daytime counterpart. The correlation coefficient of the TRMM decreased to 0.79 , the root-mean-square error increased to 3.75 , and the bias rate increased to $-9.39 \%$. All these metrics suggested that the TRMM estimates were worse at nighttime than at daytime. The PERSIANN still lacked a high-frequency appearance around $1: 1$ line at nighttime. The correlation coefficient of the PERSIANN increased to 0.57 , but the root-mean-square error increased to 5.58 and the bias rate increased to $-36.49 \%$. The above results suggested that the CMORPH maintained its accuracy throughout the day, but somehow the precision of TRMM and PERSIANN estimates degraded a little during the nighttime.

To quantitatively assess the estimate errors, we calculated the hit bias (HB), probability of detection (POD), and the false alarm rate (FAR), respectively, with the precipitation at daytime and nighttime (Figure 8). Since the precipitation amount mostly ranged from $1 \mathrm{~mm} /$ day to $60 \mathrm{~mm}$ /day, we only considered the rainfall events within this range. The deviation rate was about 1 for both TRMM and CMORPH during the daytime and nighttime. As the rain rate increased, the hit bias of PERSIANN gradually decreased to below 50\%. This indicated that the congruency of TRMM and CMORPH was much higher than that of PERSIANN. The probability of detection in the CMORPH and TRMM data was close to each other at daytime. Both of them showed a downward trend as the rain rate increased. At nighttime, the probability of detection in the CMORPH was a little bit higher than the TRMM counterpart. However, the probability of detection in the PERSIANN was much lower than the other two satellite products. This implied that the PERSIANN not only underestimated the rainfall but also missed many rainy days. Among all satellite datasets, the false alarm rate of CMORPH was the lowest and the false alarm rate of PERSIANN was the highest. As the rain rate increased, the false alarm rate in each satellite product also increased. Note that the difference in the false alarm rate between the daytime and nighttime was small.

3.1.3. Daily Timescale. The daily precipitation showed a similar pattern on the scatter plot as the nocturnal and daytime precipitation (figure omitted). Both CMORPH and TRMM had a higher KGE score than PERSIANN (Figures 9(a)-9(c)). The highest KGE score of TRMM 
TABle 3: The evaluation metrics of each satellite dataset in daytime.

\begin{tabular}{lccccccccc}
\hline & & CC & & \multicolumn{3}{c}{ RMSE } & & \multicolumn{2}{c}{ BIAS (\%) } \\
& CMORPH & TRMM & PERSIANN & CMORPH & TRMM & PERSIANN & CMORPH & TRMM & PERSIANN \\
\hline Spring & 0.81 & 0.78 & 0.48 & 2.57 & 2.90 & 4.56 & -5.31 & 5.05 & -49.04 \\
Summer & 0.82 & 0.84 & 0.57 & 3.24 & 3.10 & 5.05 & 7.77 & 4.17 & -22.97 \\
Autumn & 0.77 & 0.75 & 0.43 & 2.98 & 3.39 & 4.98 & 1.31 & 15.56 & -48.73 \\
Winter & 0.50 & 0.44 & 0.22 & 1.51 & 1.71 & 1.39 & -18.41 & -3.70 & -29.25 \\
Overall & 0.81 & 0.81 & 0.54 & 2.90 & 3.04 & 4.66 & 2.07 & 6.79 & -35.20 \\
\hline
\end{tabular}

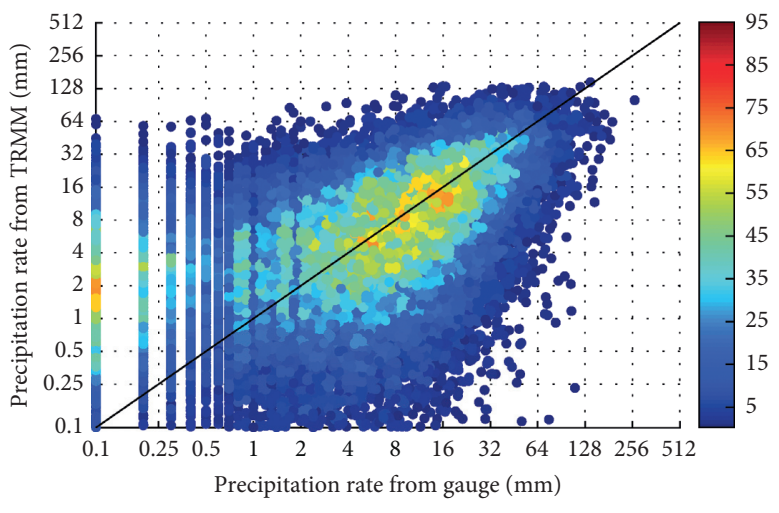

(a)

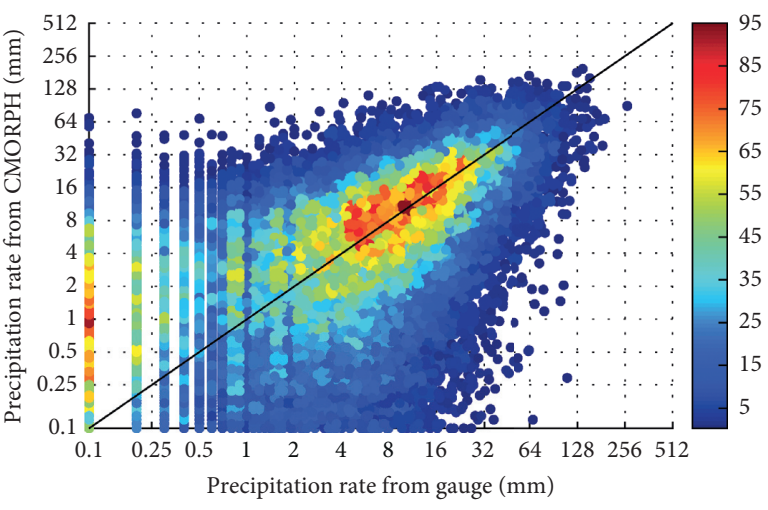

(b)

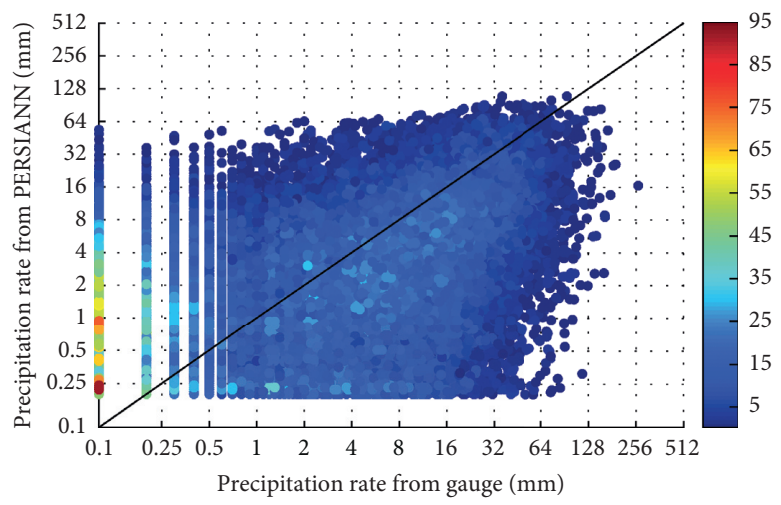

(c)

FIGURE 7: Scatter plot of the observed precipitation and (a) the TRMM, (b) the CMORPH, and (c) the PERSIANN estimates over the Three Gorges Reservoir area in the nighttime. Since the minimum scale of a rainfall gauge was $0.1 \mathrm{~mm}$, the observed precipitation less than $1 \mathrm{~mm}$ was displayed as discrete points on the scatter plot.

TABle 4: The evaluation metrics of each satellite dataset in nighttime.

\begin{tabular}{lccccccccc}
\hline & & CC & & & RMSE & & \multicolumn{2}{c}{ BIAS (\%) } \\
& CMORPH & TRMM & PERSIANN & CMORPH & TRMM & PERSIANN & CMORPH & TRMM & PERSIANN \\
\hline Spring & 0.85 & 0.80 & 0.61 & 3.21 & 3.69 & 5.23 & 5.61 & -3.39 & -29.66 \\
Summer & 0.80 & 0.79 & 0.51 & 3.97 & 3.94 & 6.35 & -5.43 & -13.96 & -35.31 \\
Autumn & 0.83 & 0.78 & 0.65 & 3.73 & 3.97 & 5.92 & 0.10 & -10.78 & -50.95 \\
Winter & 0.64 & 0.63 & 0.26 & 2.24 & 2.15 & 2.37 & 2.59 & -0.62 & -27.69 \\
Overall & 0.82 & 0.79 & 0.57 & 3.55 & 3.75 & 5.58 & -0.34 & -9.39 & -36.49 \\
\hline
\end{tabular}

appeared around the northern mainstream region, whereas the lowest KGE score was distributed over the western reservoir area. The KGE score of CMORPH was a bit higher than TRMM over the entire reservoir area. Nevertheless, the
KGE score of PERSIANN was less than 0.4 in most parts of the reservoir area. The average KGE score over the Three Gorges Reservoir area was 0.67 for TRMM, 0.69 for CMORPH, and 0.33 for PERSIANN. Judging from Theil's U 


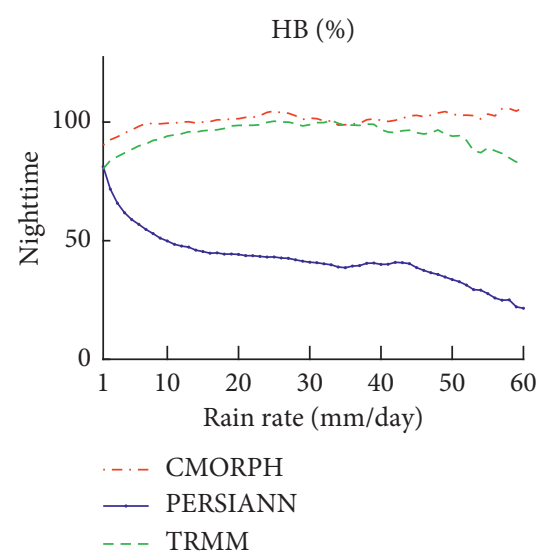

(a)

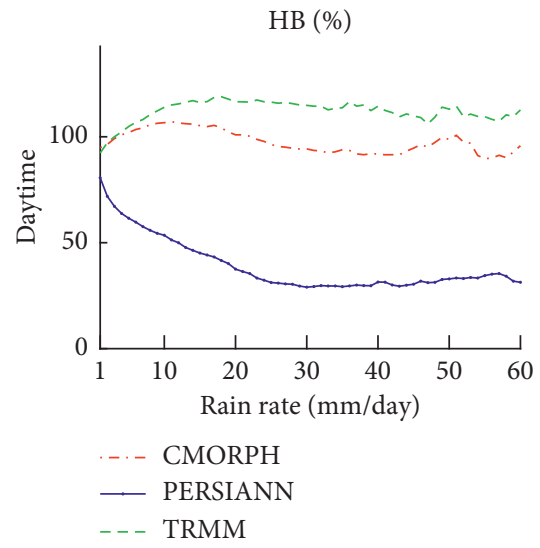

(d)

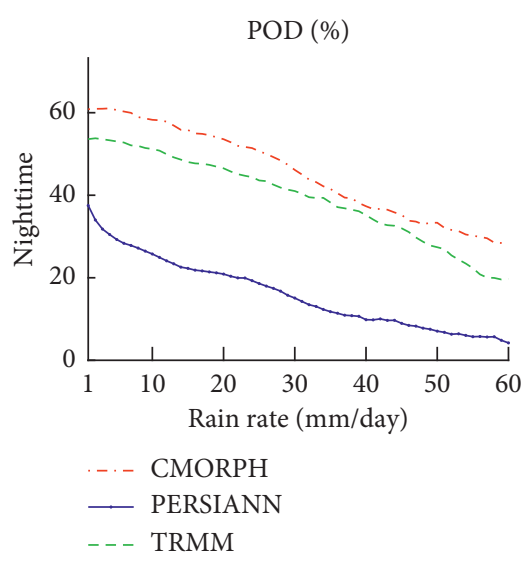

(b)

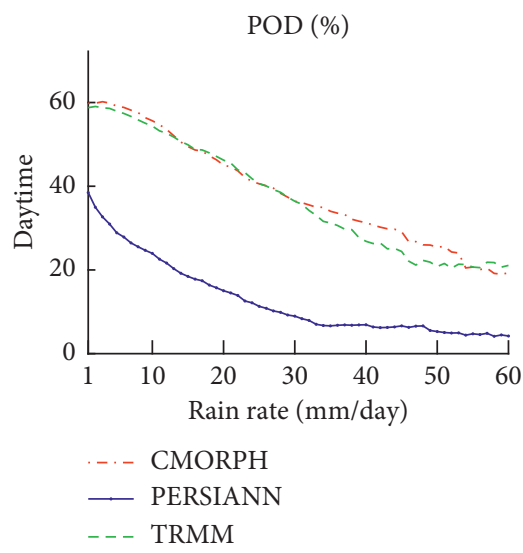

(e)

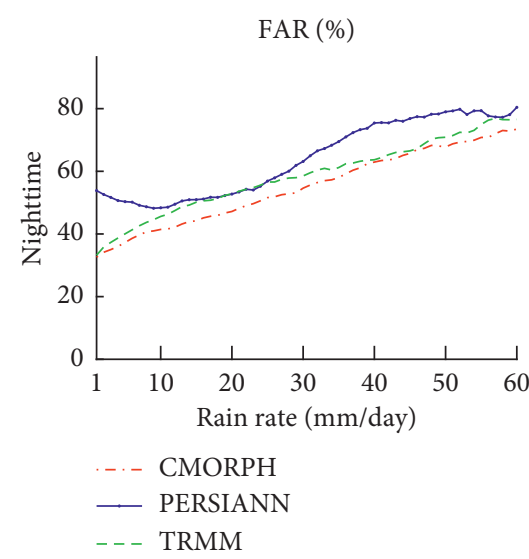

(c)

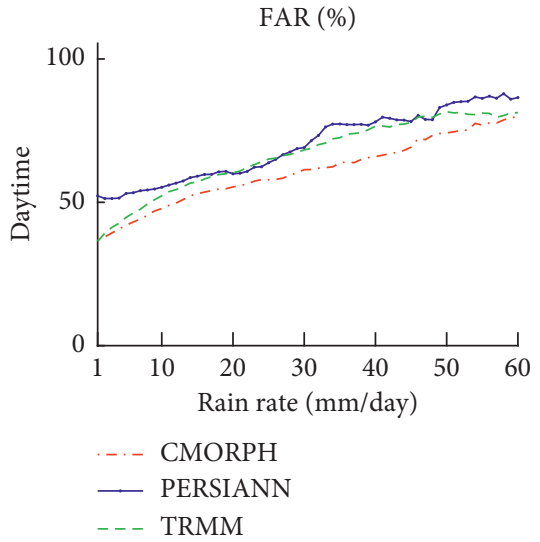

(f)

Figure 8: (a) The hit bias, (b) the probability of detection, and (c) the false alarm rate of each satellite product at nighttime. (d) The hit bias, (e) the probability of detection, and (f) the false alarm rate of each satellite product at daytime.

score, the performance of CMORPH was generally the best of all, followed by TRMM and then PERSIANN (Figures 9(d)-9(f)). Given the spatial patterns of Theil's U and KGE scores, the CMORPH estimates best represented the precipitation over the northern mainstream and central southern edge of the reservoir area. The mean Theil's U score was 0.75 for TRMM, 0.72 for CMORPH, and 1.34 for PERSIANN. The above results indicated that both TRMM and CMORPH could capture the temporal variability and the average intensity of daily rainfall in the Three Gorges Reservoir area.

The PDF of observed rainless cases is about $60 \%$ over the research area (Figure 10). Both CMORPH and PERSIANN showed a similar PDF for no-rain cases, whereas the TRMM tended to overestimate the frequency of no-rain events by a few percent. This indicated that the TRMM estimates missed some rainy cases. The capability of rainfall detection differed among the satellite products. For example, the TRMM could reproduce the PDF of moderate-to-heavy rainfall events reasonably well, but it obviously underestimated the PDF of light rain. In contrast, the PERSIANN overestimated the light rain events but underestimated the PDF of moderate rainfall and above. The CMORPH showed the best performance in the PDF of precipitation among all satellite products.

The performance of satellite products could be summarized with the Taylor diagram (Figure 11). Both TRMM and CMORPH presented a relatively good performance in reproducing the rainfall of different intensities. These two satellite products showed the highest correlation (over 0.6) for the light rain, the smallest root-mean-square deviation (RMSD) (about 1.1), and the standard deviation closest to 1 for the heavy rain. In contrast, the PERSIANN showed a poor conformity with the observation. The above results suggested that TRMM and CMORPH were better than PERSIANN over the Three Gorges Reservoir area.

The hit bias, probability of detection, and the false alarm rate on a daily timescale resembled the 12-hourly counterpart (Figure 12). The hit bias of CMORPH and TRMM 


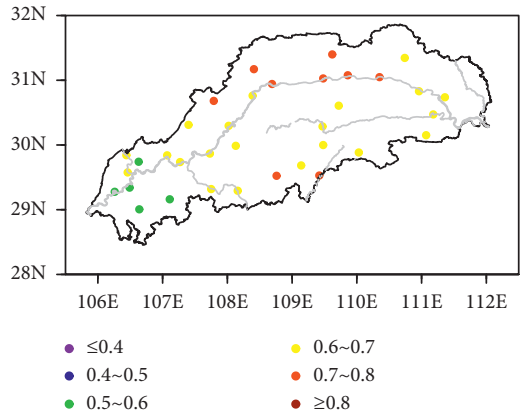

(a)

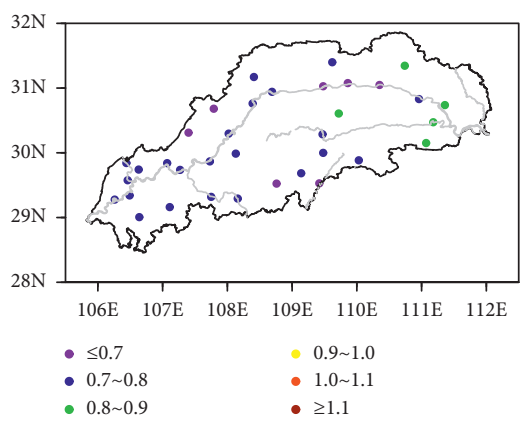

(d)

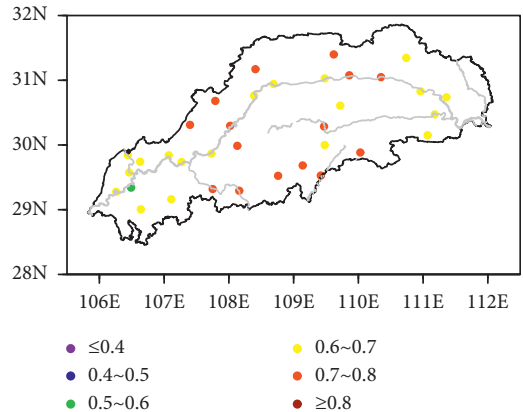

(b)

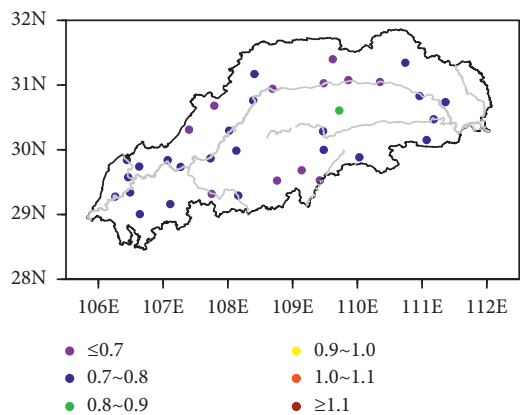

(e)

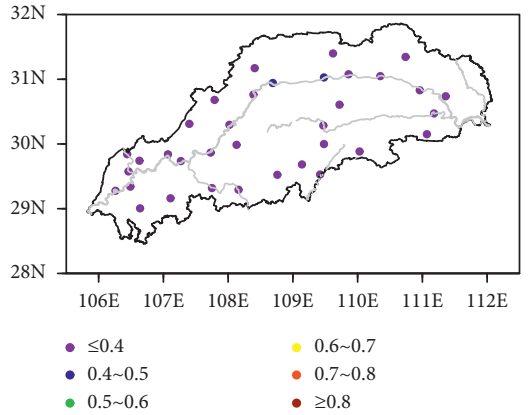

(c)

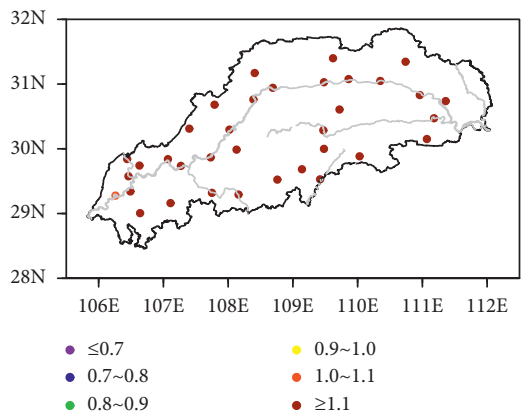

(f)

FIGURE 9: The KGE scores at each gauge station for (a) TRMM, (b) CMORPH, and (c) PERSIANN during the period 2001-2016. Theil's U score at each gauge station for (d) TRMM, (e) CMORPH, and (f) PERSIANN during the period 2001-2016.

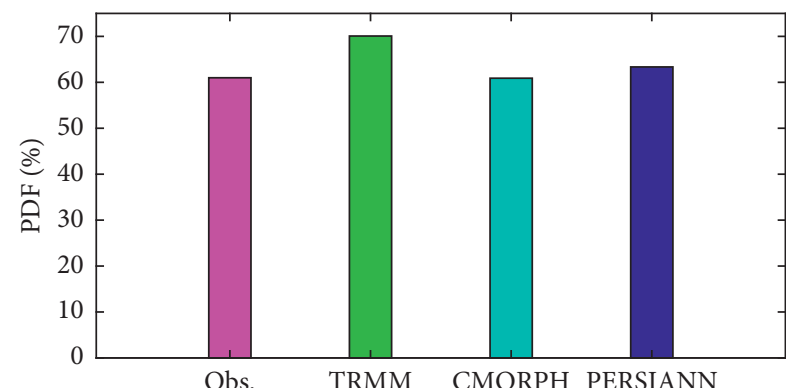

(a)

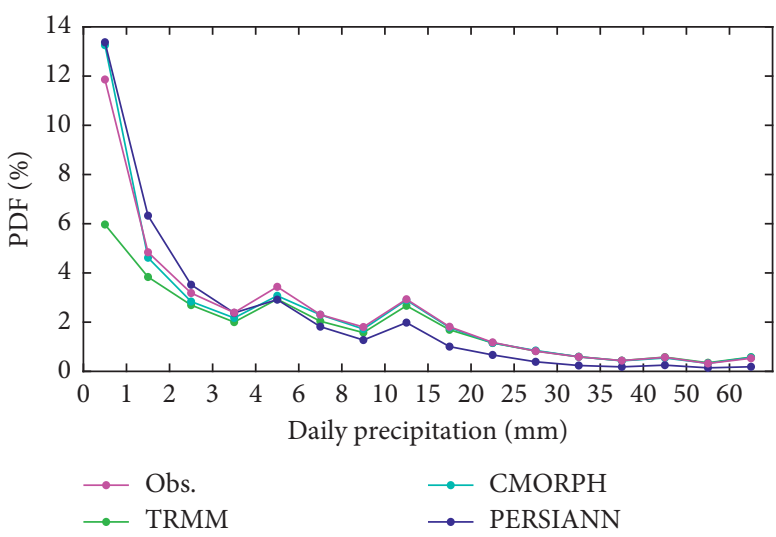

(b)

Figure 10: Probability density function of daily precipitation for (a) no-rain and (b) precipitation of different intensities derived from observation and satellite estimates.

remained around $100 \%$ for the rain rates from $1 \mathrm{~mm} /$ day to $60 \mathrm{~mm} /$ day. As the precipitation rate increased to $60 \mathrm{~mm} /$ day, the probability of detection decreased by around $18 \%$ for both CMORPH and TRMM. Accordingly, the false alarm rate increased to around 50\%. The PERSIANN data quality was still the lowest among all satellite products.

3.1.4. Monthly Timescale and above. The time series of the correlation coefficient, bias rate, and the root-mean-square error for each satellite product are shown in Figure 13. Most of the time, the correlation coefficient of TRMM was the highest $(>0.5)$ and the correlation coefficient of PERSIANN was the lowest $(<0.3)$ among all satellite products. The correlation coefficient of CMORPH was only a little bit lower than TRMM. This indicated that the CMORPH and TRMM could capture the spatial pattern of monthly precipitation over the Three Gorges Reservoir area, but the PERSIANN data differed from the observation more obviously than the other two satellite products. The bias rate of TRMM was close to that of CMORPH, both around the 0 lines except for January 2011 and January 2013 when the CMORPH 


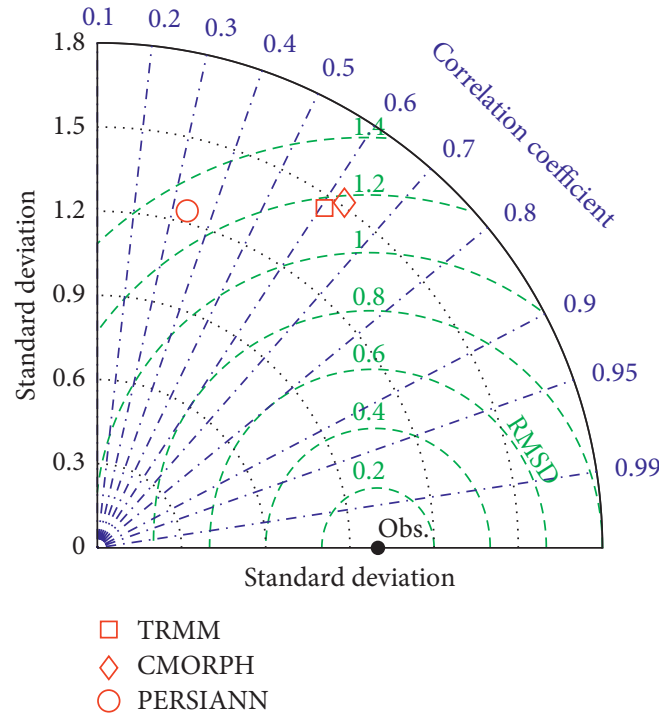

(a)

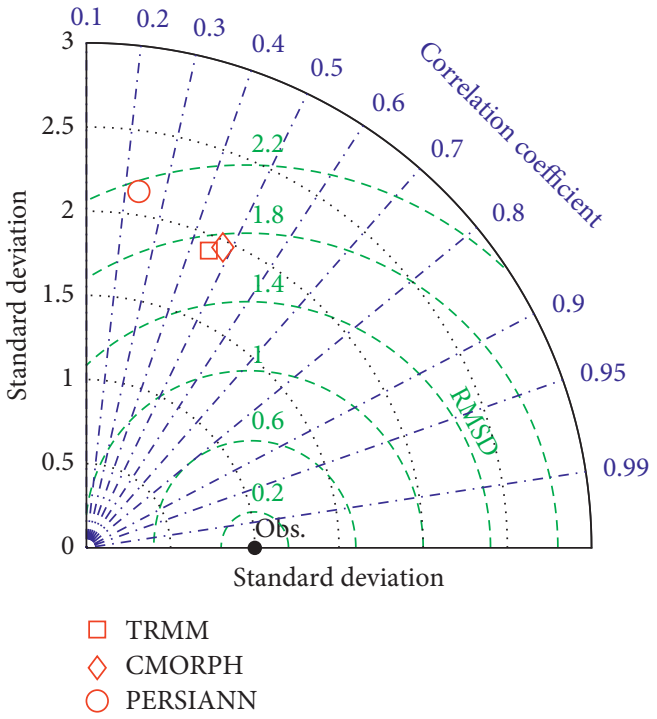

(b)

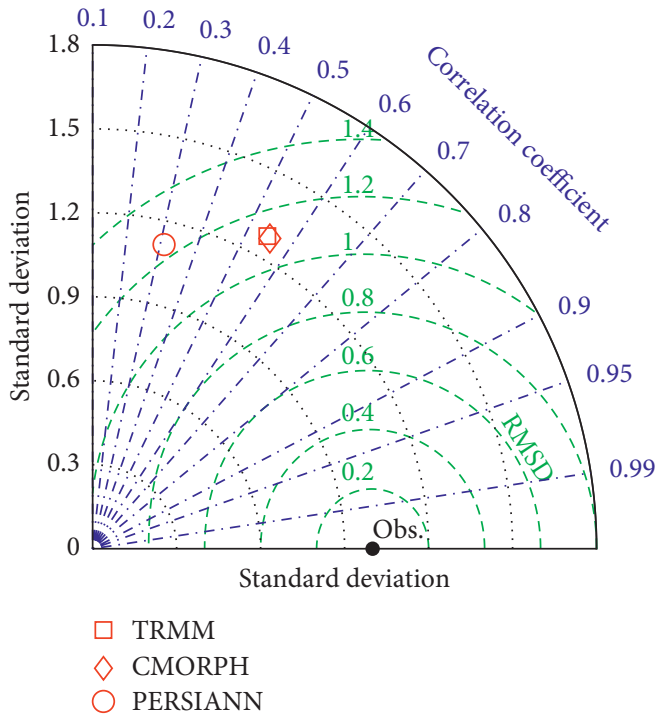

(c)

FIGURE 11: Taylor diagrams for the satellite estimates of (a) light rainfall, (b) moderate rainfall, and (c) heavy rainfall and above derived from the area-average daily precipitation.

apparently overestimated the rainfall. In contrast, the bias rate of PERSIANN was mostly around $-50 \%$, which implied that the PERSIANN tended to underestimate the rainfall. The root-mean-square error (RMSE) of TRMM was the smallest among all satellite products, no more than $2 \mathrm{~mm} /$ day most of the time. The RMSE of CMORPH had a similar fluctuation tendency as that of TRMM but noticeably higher than the TRMM in a few months. The PERSIANN had the largest RMSE, basically between $2 \mathrm{~mm}$ /day and $6 \mathrm{~mm}$ /day.

The spatial pattern of seasonal mean precipitation rate was generally reproduced in the CMORPH and TRMM data (Figure 14). Only the winter season showed an obvious deviation from the observation, in which the precipitation over the western Three Gorges Reservoir area was underestimated. The CMORPH also overestimated the precipitation over the central Three Gorges Reservoir area. The PERSIANN underestimated the seasonal rainfall amount throughout the year. In general, the TRMM precipitation best coincided with the observation through the four seasons (Figure 15). The TRMM data also had the smallest RMSE and the lowest bias rate except for summer, when the bias rate of CMORPH was the lowest of all. In consistency with the spatial pattern, all satellite products underestimated the winter precipitation to a varying degree. The above results evinced that the TRMM product was the best for the seasonal timescale.

The percentage of occurrence of different precipitation rates was calculated for each season (Figure 16). The PERSIANN overestimated the occurrence of light rain but underestimated the probability of moderate and heavy rains. 


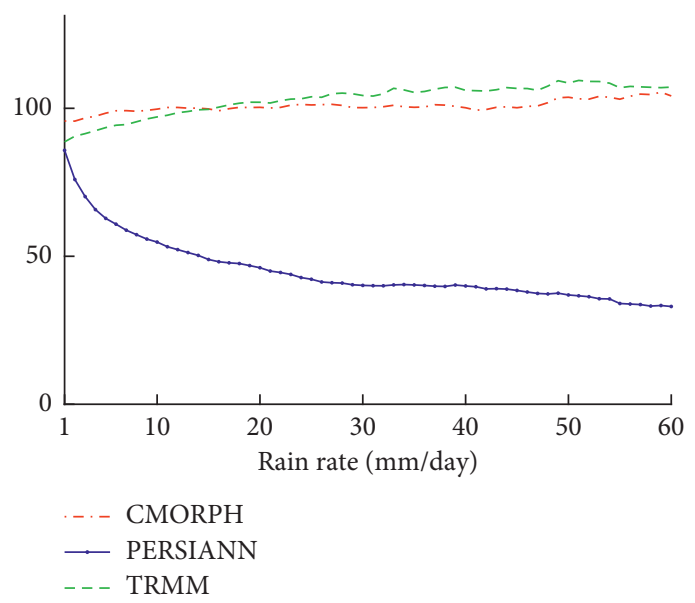

(a)

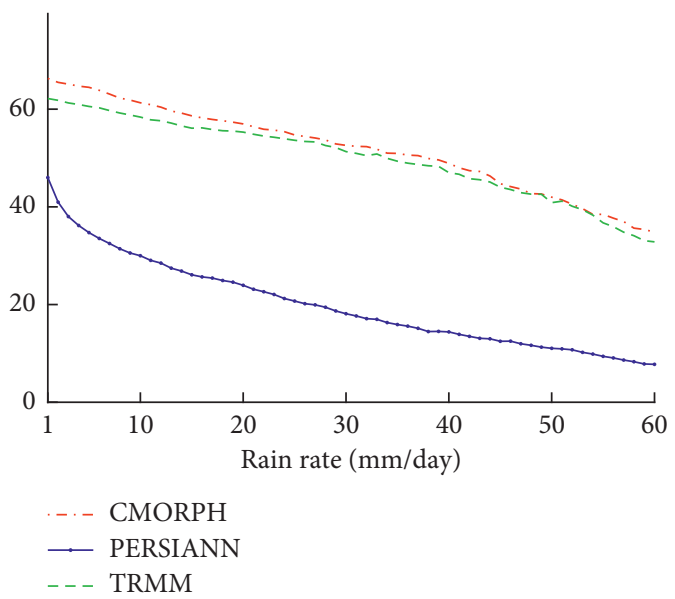

(b)

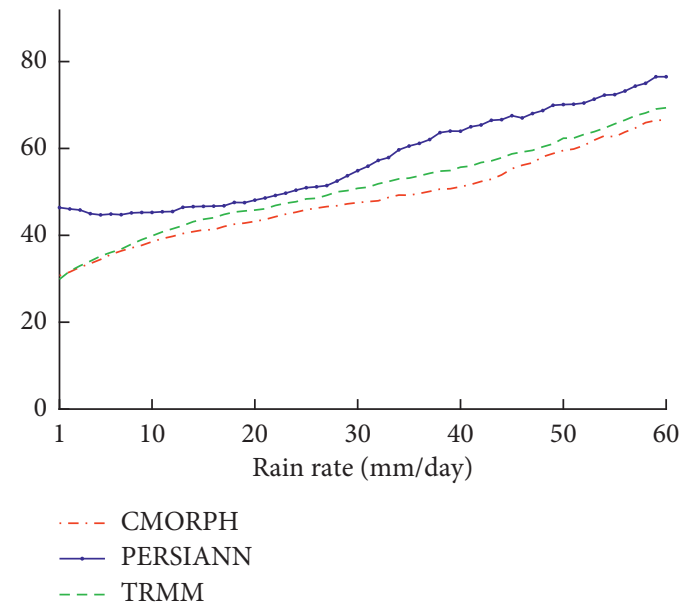

(c)

FIGURE 12: (a) The hit bias, (b) the probability of detection, and (c) the false alarm rate of each satellite product on a daily timescale.

The profiles of TRMM and CMORPH resembled each other, but less moderate rain was detected by TRMM than CMORPH. Among all satellite products, the CMORPH estimates of rainfall occurrence were closest to the observation in winter and spring, and the TRMM estimates were the best in summer and autumn.

3.2. Rainy-Day Detection. The rainy events most frequently occur in the southern reservoir area, around the tributary stations such as Hefeng, Laifeng, and Nanchuan (Figure 17(a)). The eastern reservoir area had the least rainy days of the entire area. In comparison to the observation, both TRMM and CMORPH showed the rainy-day maximum over the central reservoir area (Figures 17(b) and 17(c)). The rainy-day pattern of PERSIANN was almost opposite to the observation, with the maximum over the northern reservoir area and the minimum over the southwestern reservoir area (Figure 17(d)). In all satellite estimates, the occurrence of rainy events was more frequent in the east than in the west. This characteristic mainly resulted from the bias of rainy-day detection in spring, autumn, and winter. In these three seasons, both CMORPH and TRMM showed the rainy-day maximum over the central reservoir area and the rainy-day minimum in the west (Figure 18). The PERSIANN obviously underestimated the rainy events in autumn, with rainy day less than 20 in most areas. In contrast, the observed rainy day ranged from 24 to 32 . In spring and winter, the PERSIANN rainy-day maximum was distributed in the north, which resulted in the northward 


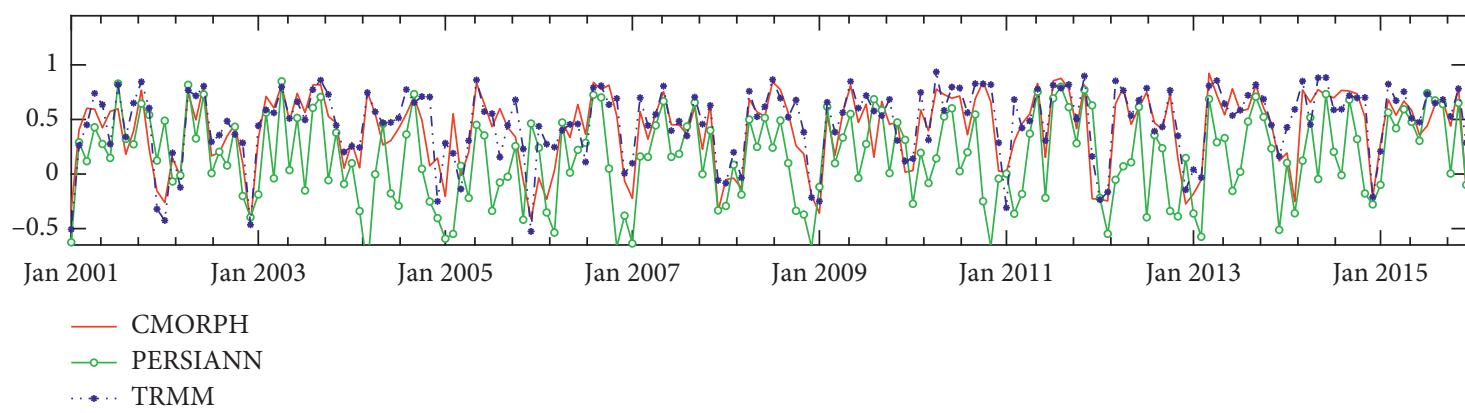

(a)

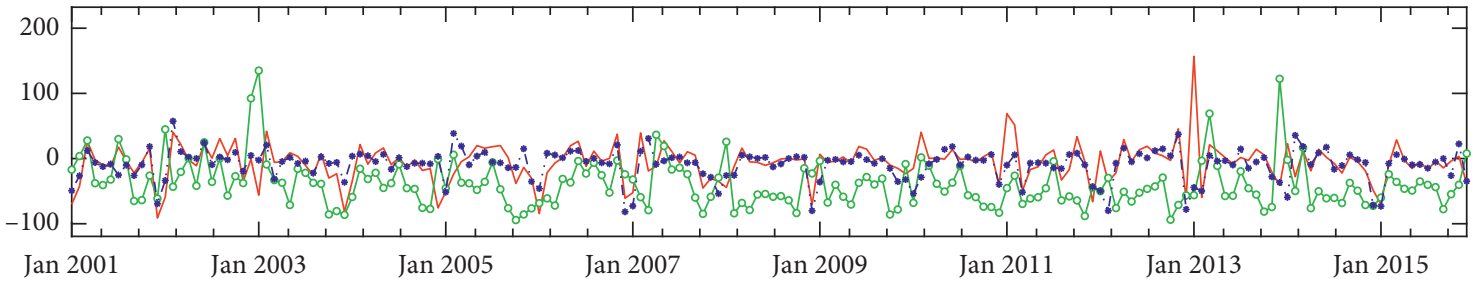

- CMORPH

$\multimap$ PERSIANN

... TRMM

(b)

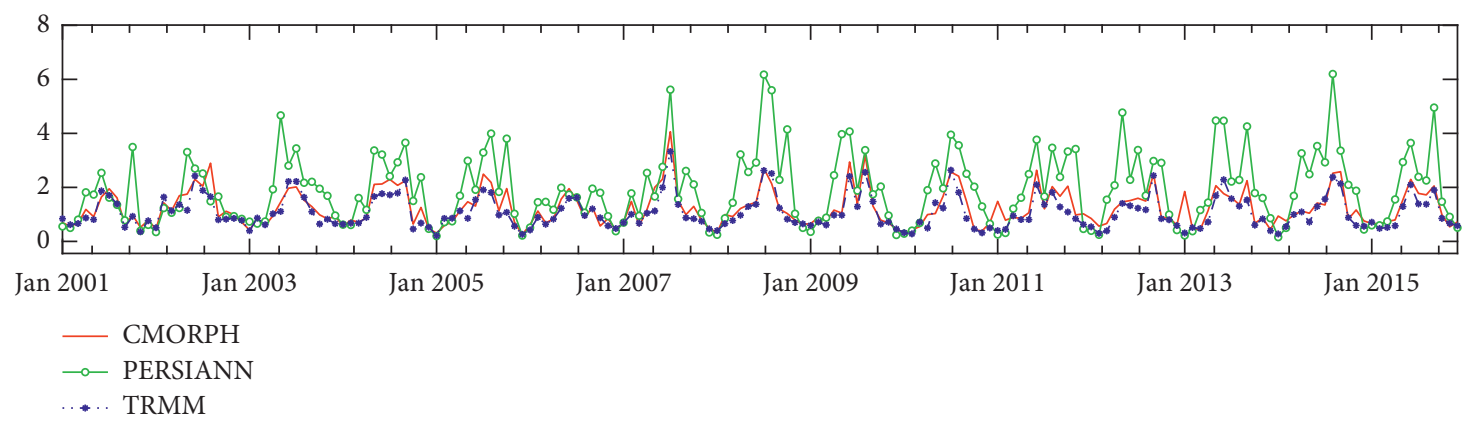

(c)

FIGURE 13: Time series of (a) correlation coefficient, (b) bias rate, and (c) root-mean-square error of each satellite product on a monthly timescale.

shift of rainy-day maximum in the whole year.

The frequency of occurrence of each rainfall magnitude was calculated on the monthly basis (Figure 19). In comparison to the observation, the TRMM tended to overestimate the frequency of rainy events in the winter half year (October-next March). The CMORPH was inclined to overestimate the frequency of moderate rains during the rainy season (May-October) whereas the PERSIANN overestimated the frequency of light rains but underestimated the frequency of heavy rains and above. These results suggested that the satellite estimates of rainy-day frequency were close to the observation but still had nonnegligible biases.

3.3. Extreme Precipitation Detection. The maximum 5-day precipitation (RX5day) ranged between 100 and 200 over the reservoir area (Figure 20(a)). The RX5day values were greater in the western area than in the eastern area. These characteristics of the RX5day spatial pattern were generally consistent with Ren et al. [44]. In comparison to the observation, the CMORPH estimate was the most realistic and accurate among all satellite products (Figures 20(b)$20(d))$. In contrast, the TRMM underestimated the maximum precipitation amount especially around Beibei, Shapingba, Banan, Kaizhou, Enshi, and Jianshi observation stations. At these stations, the maximum rainfall amount was underestimated for about $50 \mathrm{~mm}$. This bias was even worse in the PERSIANN estimate, in which most stations had the RX5day less than $100 \mathrm{~mm}$.

The observed extreme precipitation was heavier in the east than in the west of the reservoir area (Figure 21(a)). This spatial pattern resembled Liu et al. [49] in relation to the magnitude and distribution of R95. All satellite estimates of extreme precipitation deviated from the observation, where the CMORPH bias was the smallest (Figures 21(b)-21(d)). The estimated error of CMORPH data was mainly the overestimation of extreme precipitation over the western reservoir area. This bias became more obvious in the TRMM data, which overestimated the extreme rainfall almost by $100 \mathrm{~mm}$ around Qijiang, Wulong, Fuling, and Fengdu 

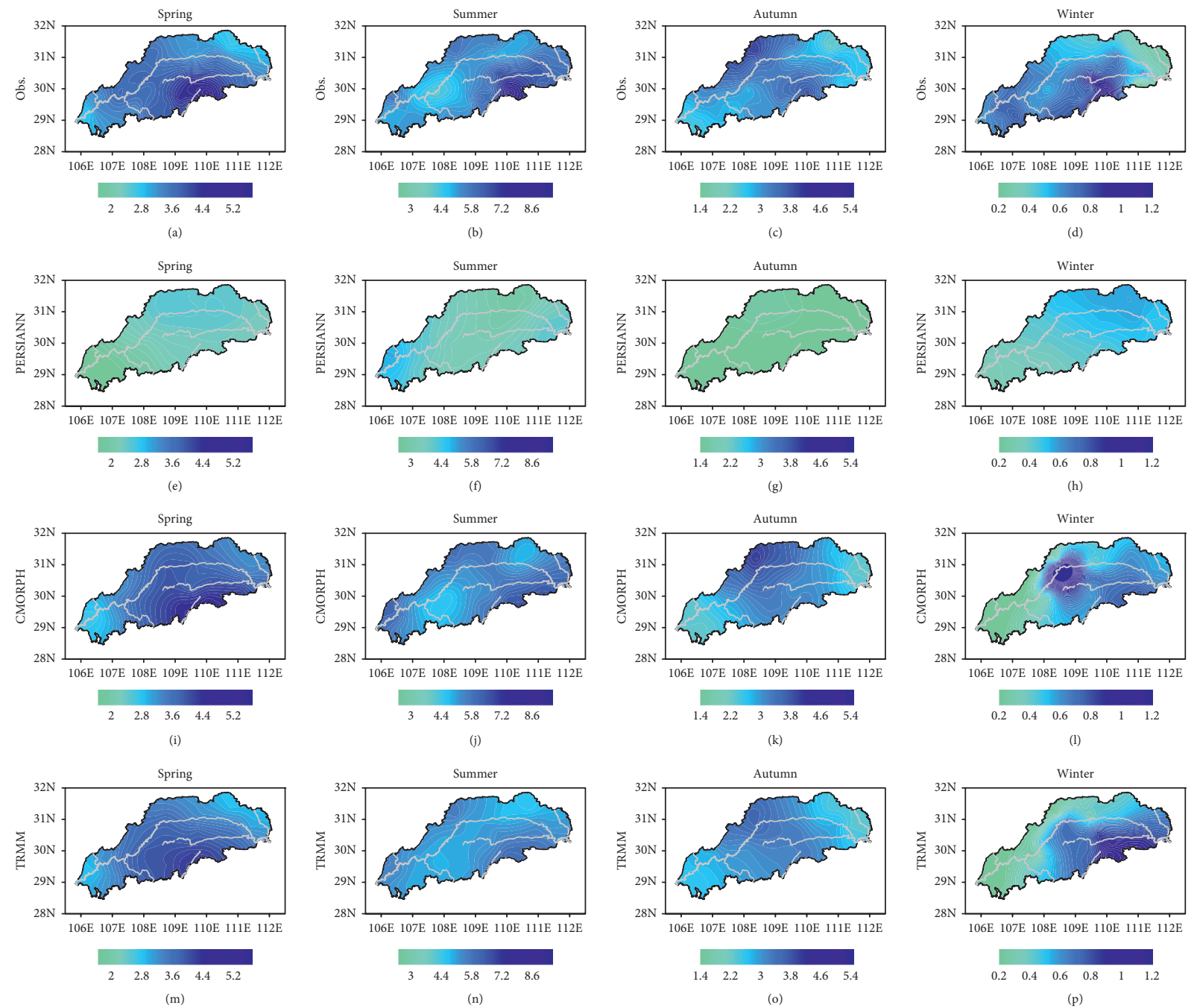

FIgURE 14: The spatial distribution of seasonal mean precipitation (units: mm/day) for each season.

stations. Conversely, the PERSIANN underestimated the extreme precipitation by about $150 \mathrm{~mm}$ over the entire reservoir area.

The persistent rainy days (CWD) over the reservoir area were longer in the south than in the north (Figure 22(a)). The separatrix between the north and the south was around the Yangtze River. The TRMM tended to underestimate the CWD in the upstream area (Figure 22(b)). For example, the TRMM estimates were one day shorter than the observation at Qijiang and Banan stations and two days shorter than the observation at Shapingba and Nanchuan stations. Likewise, the CMORPH overestimated the CWD in the upstream area by about 1 day and also in the downstream area by $1-2$ days (Figure 22(c)). The CMORPH overestimation in the downstream area covered Zigui, Yichang, Changyang, and Badong stations. In contrast, the PERSIANN underestimated the CWD over the southern reservoir area by about 1 day around Nanchuan, Pengshui, Qianjiang, and
Laifeng stations and about 2 days around Qijiang and Wulong stations (Figure 22(d)). The above results suggested that each satellite product had its own bias in estimating the extreme precipitation, and the CMORPH was comparatively the best of all.

The maximum precipitation during the daytime, nighttime, and the whole day was given in Table 5. Among all satellite products, the CMORPH was closest to the observation in the daytime (bias around $2 \mathrm{~mm}$ ). The PERSIANN estimates were the best of all during the nighttime (bias around $2 \mathrm{~mm}$ ) and the whole day (bias around $4 \mathrm{~mm}$ ). Both TRMM and CMORPH overestimated the maximum rainfall for all three periods, but instead, the PERSIANN underestimated the maximum rainfall. It could be inferred from the rainfall data (Table 1) that the daily biases of TRMM and PERSIANN were mostly attributed to the estimate errors in daytime whereas the daily bias of CMORPH was basically related to the estimate errors in the nighttime. 


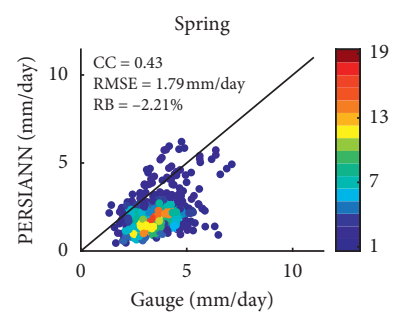

(a)

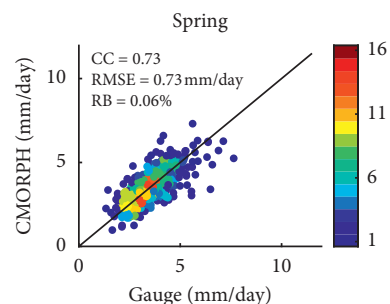

(e)

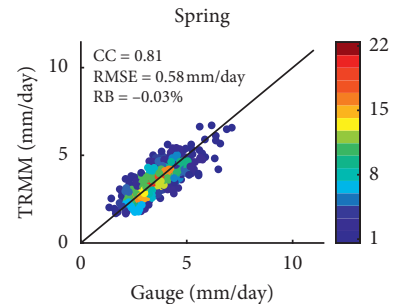

(i)

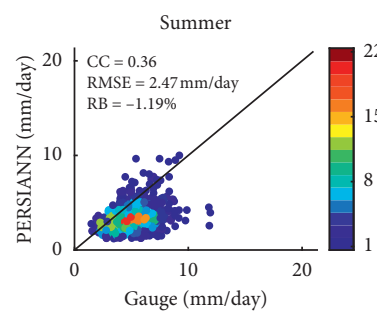

(b)

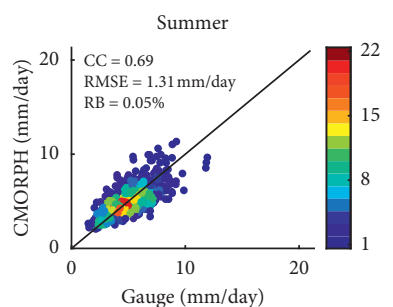

(f)

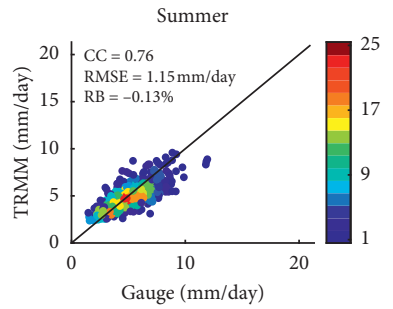

(j)

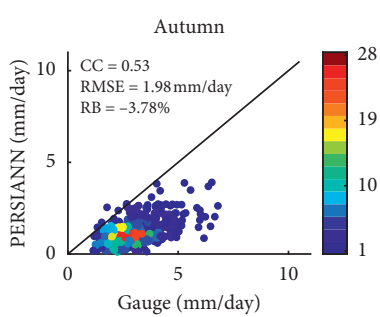

(c)

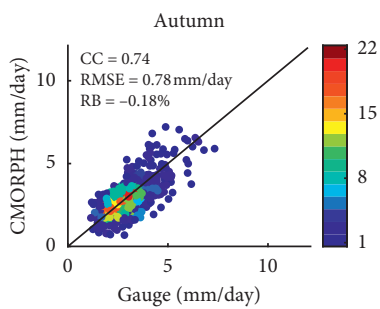

(g)

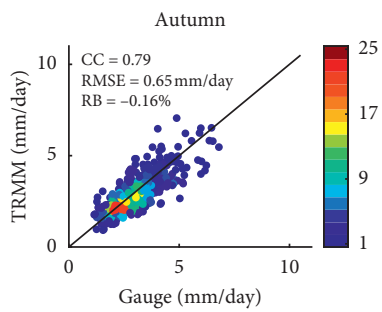

(k)

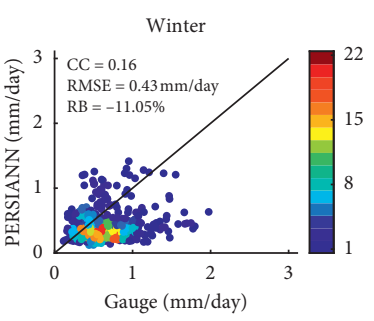

(d)

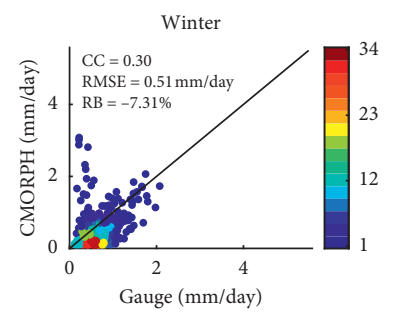

(h)

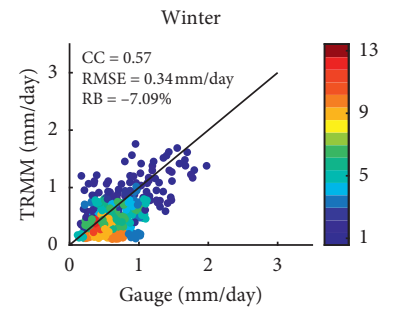

(1)

FIGURE 15: Scatter plot of average daily precipitation in spring (a, e, i), summer (b, f, j), autumn (c, g, k), and winter (d, h, l) in the Three Gorges Reservoir area.
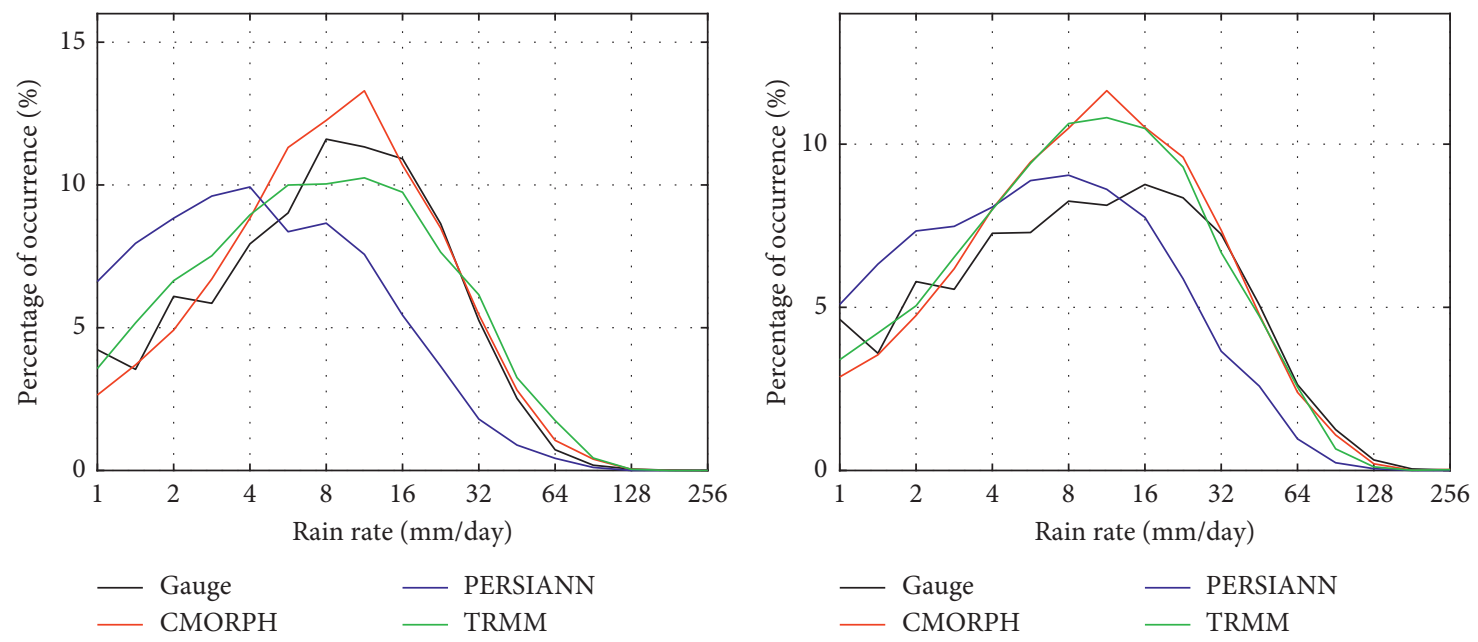

(a)

(b)

Figure 16: Continued. 


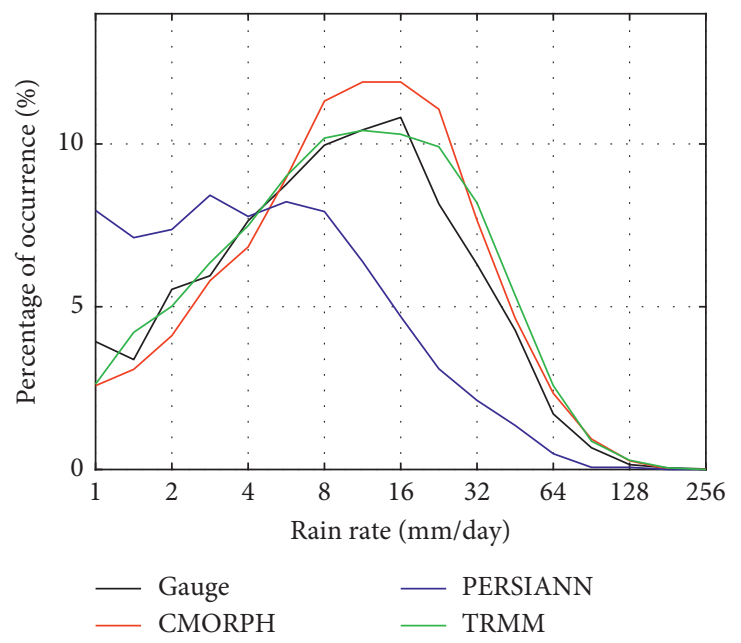

(c)

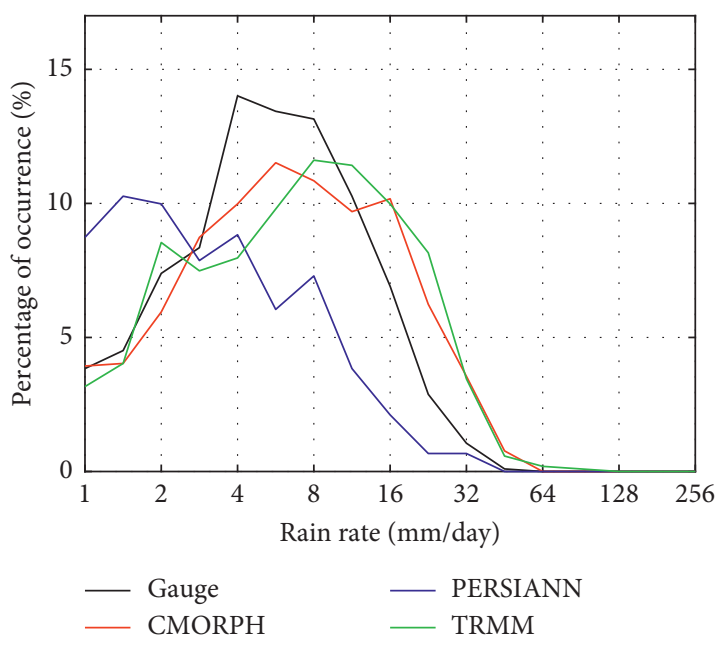

(d)

FIGURE 16: The percentage of rainfall occurrence in (a) spring, (b) summer, (c) autumn, and (d) winter in the Three Gorges Reservoir area.

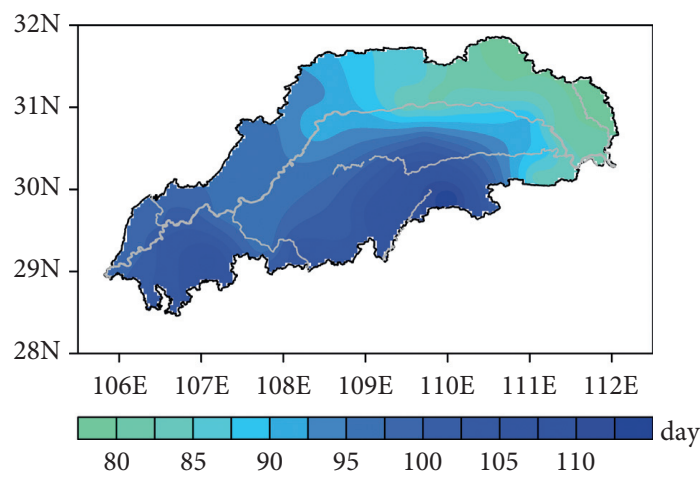

(a)

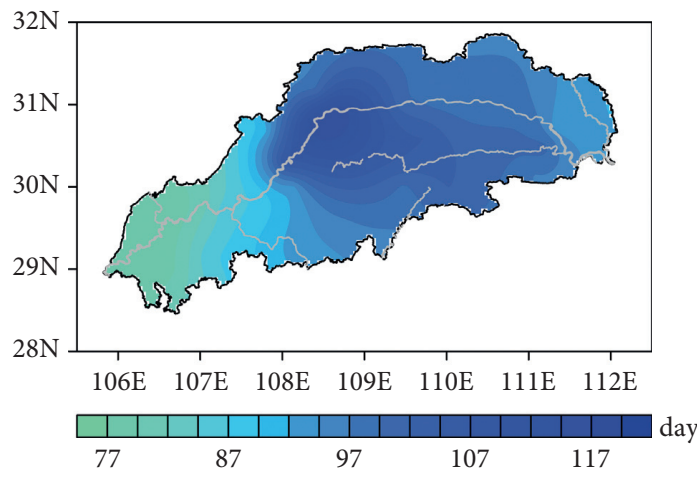

(c)

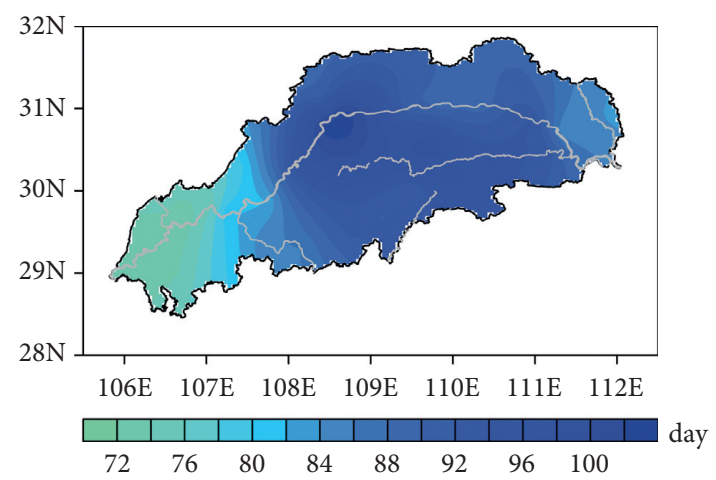

(b)

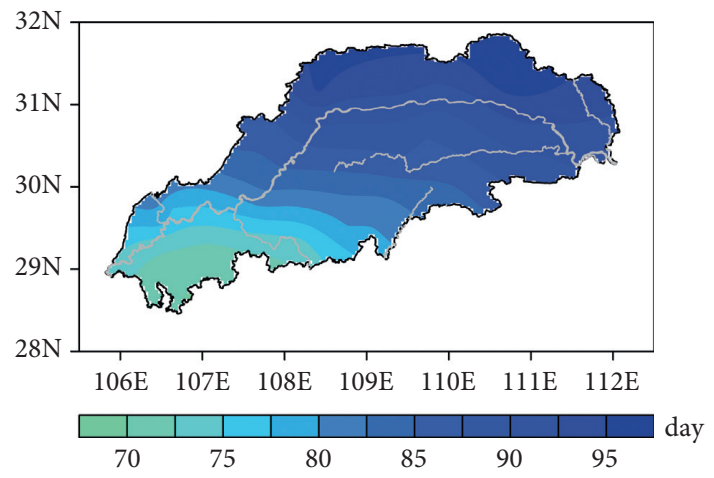

(d)

FIGURE 17: The spatial distribution of annual mean rainy days (based on the rainfall amount greater than or equal to $1 \mathrm{~mm}$ ) in (a) gauge observation, (b) TRMM, (c) CMORPH, and (d) PERSIANN. 

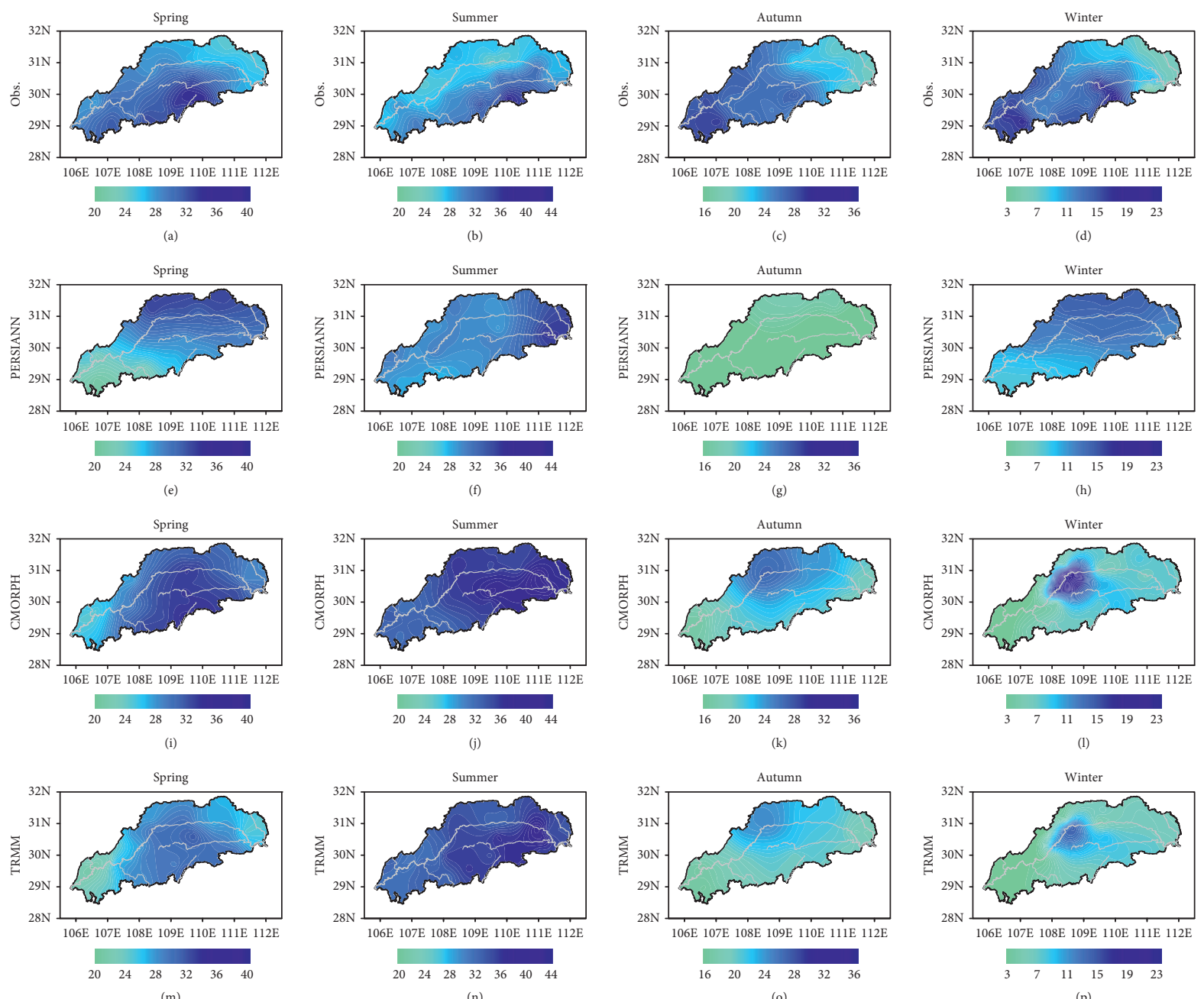

FIGURE 18: The spatial distribution of seasonal mean rainy day (based on the rainfall amount greater than or equal to $1 \mathrm{~mm}$ ) in (a-d) gauge observation, (e-h) PERSIANN, (i-l) CMORPH, and (m-p) TRMM. 


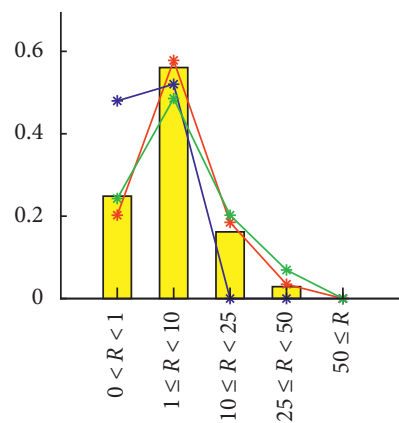

Rain rate (mm/day)

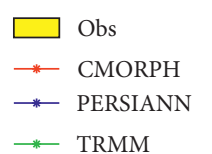

(a)

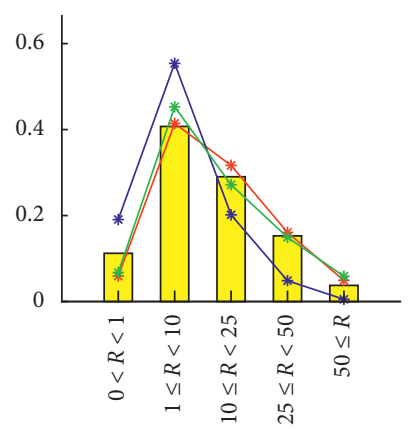

Rain rate ( $\mathrm{mm} /$ day)

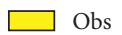

- CMORPH

* PERSIANN

* TRMM

(e)

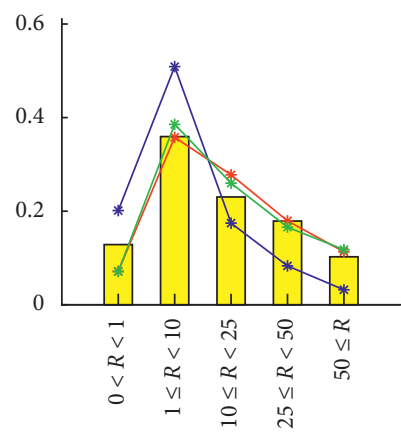

Rain rate (mm/day)

$\square$ Obs

* CMORPH

* PERSIANN

* TRMM

(i)

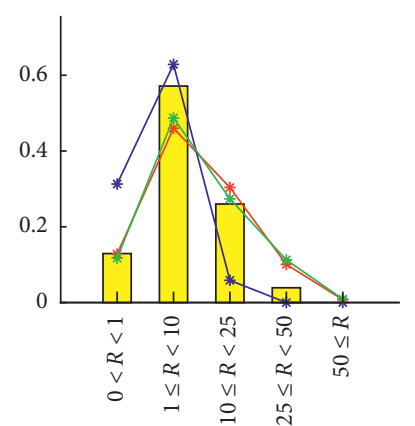

Rain rate (mm/day)

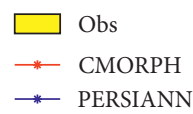

* PERSIANN

* TRMM

(b)

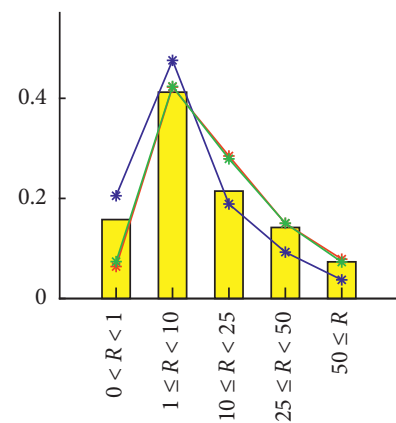

Rain rate (mm/day)

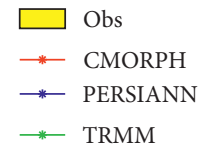

(f)

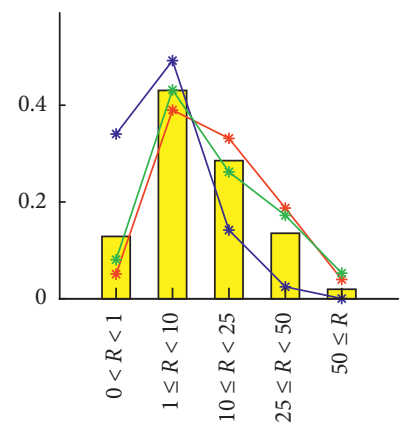

Rain rate (mm/day)

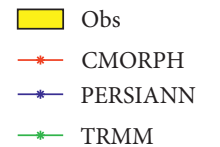

(j)

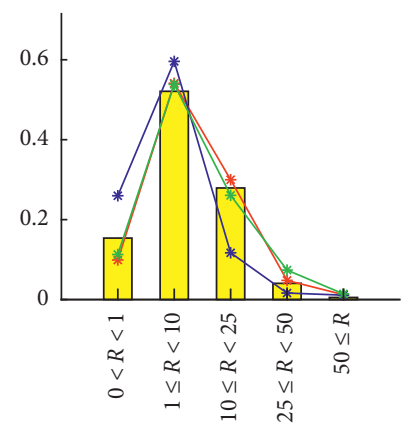

Rain rate (mm/day)

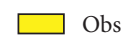

- - CMORPH

- - PERSIANN

* TRMM

(c)

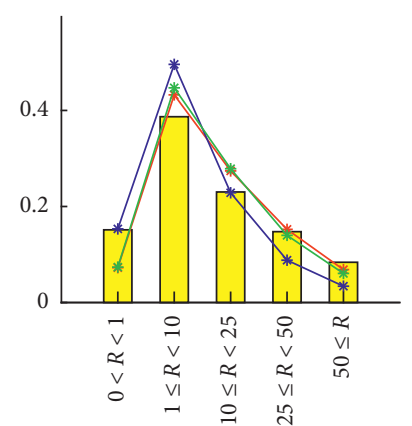

Rain rate (mm/day)

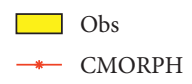

* PERSIANN

— TRMM

(g)

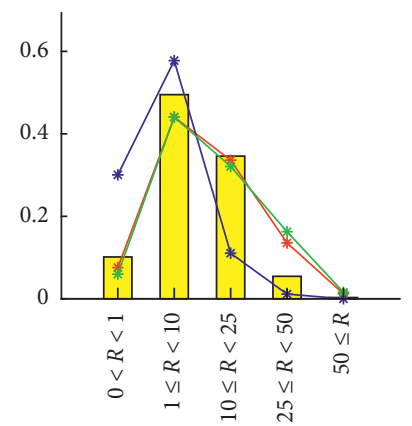

Rain rate (mm/day)

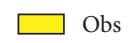

- - CMORPH

* PERSIANN

* TRMM

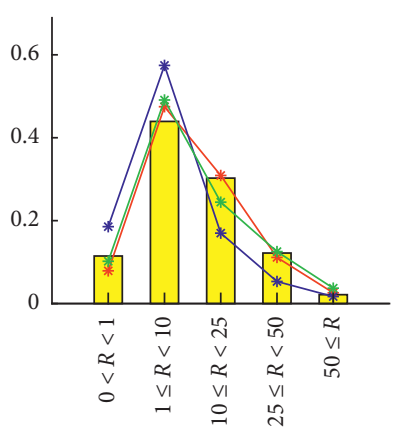

Rain rate (mm/day)

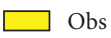

* CMORPH

* PERSIANN

— TRMM

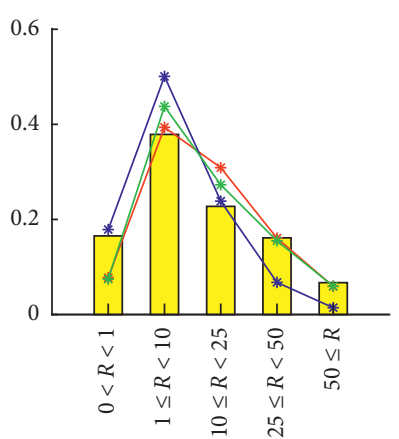

Rain rate (mm/day)

$\square$ Obs

— CMORPH

* PERSIANN

— TRMM

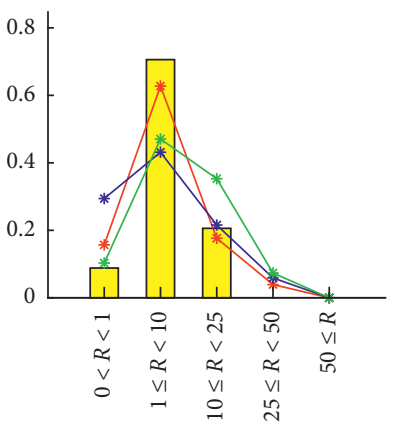

Rain rate (mm/day)

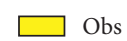

* CMORPH

* PERSIANN

$\rightarrow$ TRMM

FIGURE 19: The frequency of occurrence of drizzle $(0<R<1)$, light rain $(1 \leq R<10)$, moderate rain $(10 \leq R<25)$, heavy rain $(25 \leq R<50)$, and above $(50 \leq R)$ for each month. In each subplot, the yellow bar denoted the gauge observation, the red line with an asterisk denoted the CMORPH, the blue line with an asterisk denoted the PERSIANN, and the green line with an asterisk denoted the TRMM. 


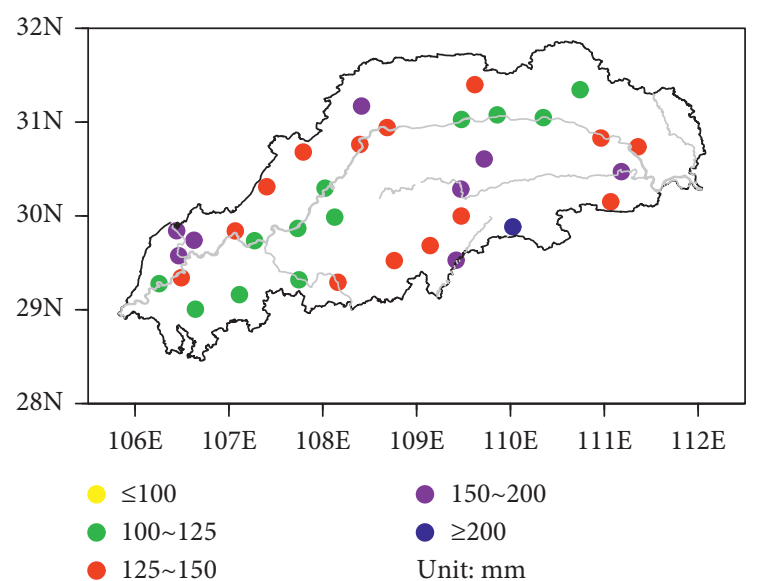

(a)

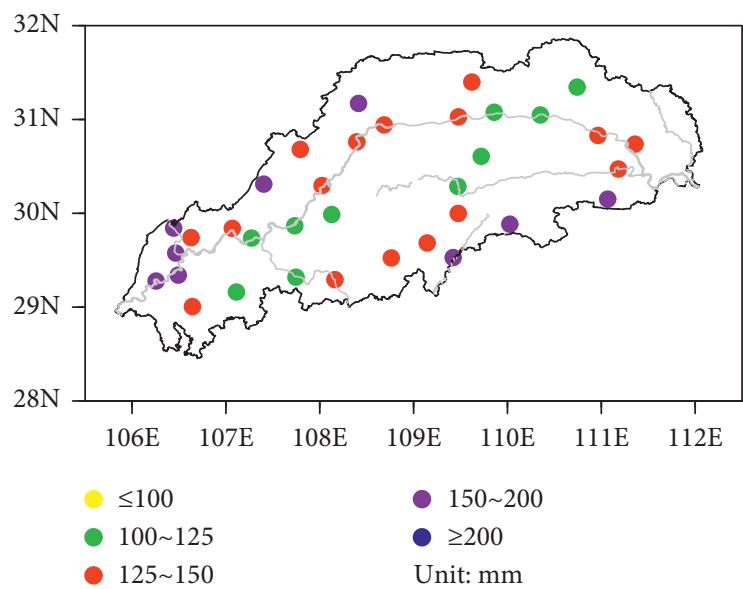

(c)

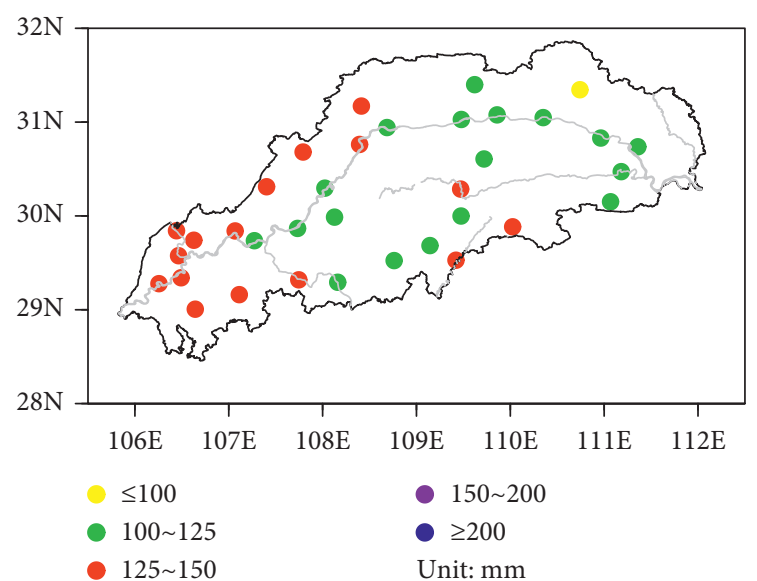

(b)

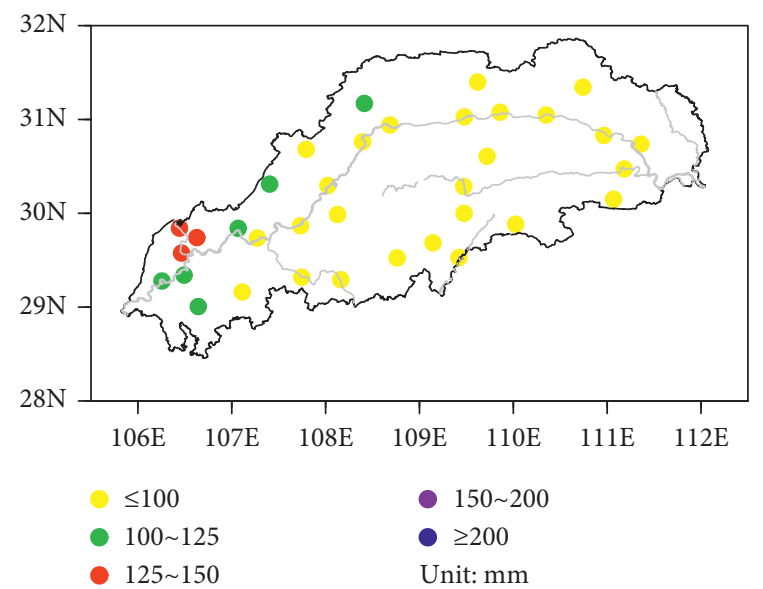

(d)

FIGURE 20: The spatial distribution of RX5day calculated from (a) gauge observation, (b) TRMM, (c) CMORPH, and (d) PERSIANN at each rain-gauge station.

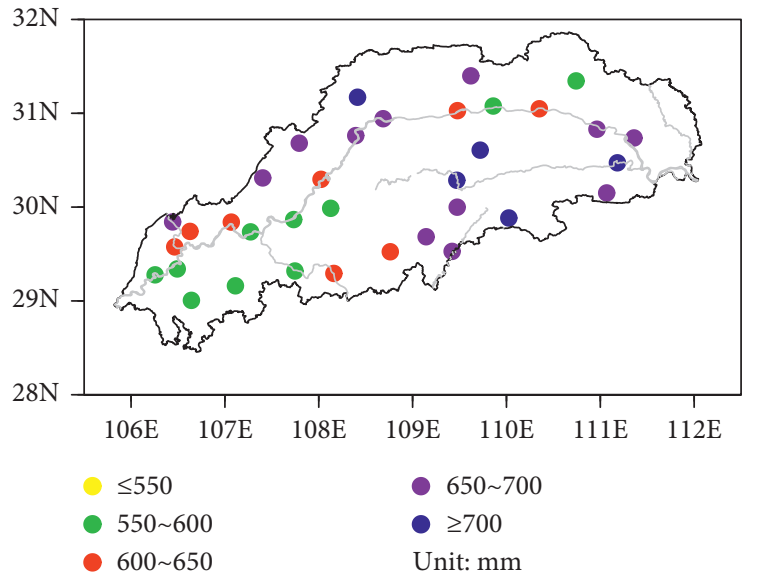

(a)

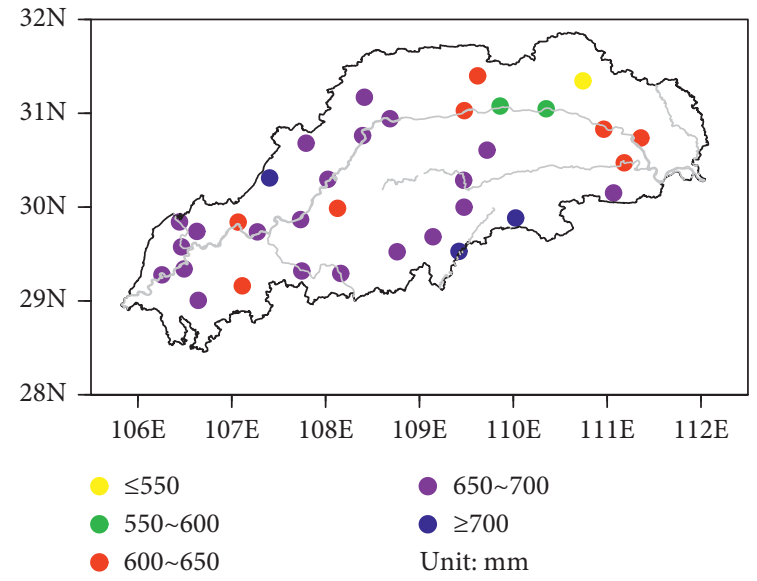

(b)

FIgure 21: Continued. 


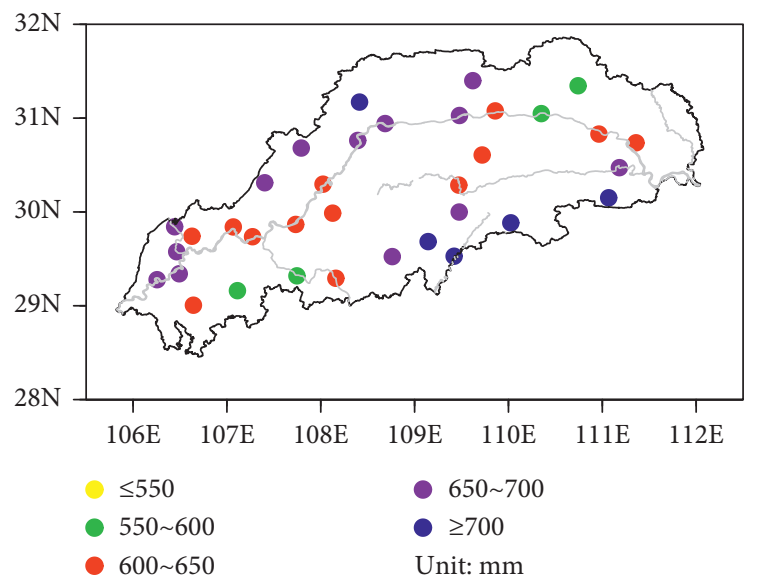

(c)

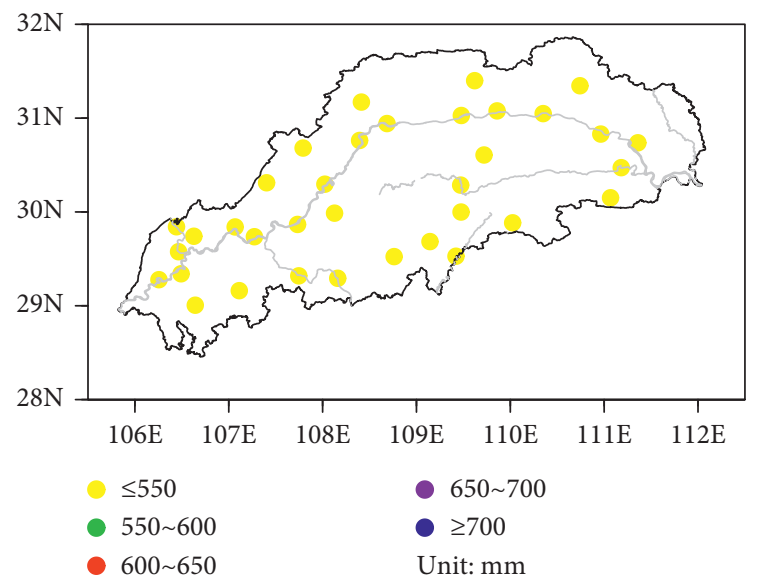

(d)

FIgURE 21: The spatial distribution of R95 calculated from (a) gauge observation, (b) TRMM, (c) CMORPH, and (d) PERSIANN at each rain-gauge station.

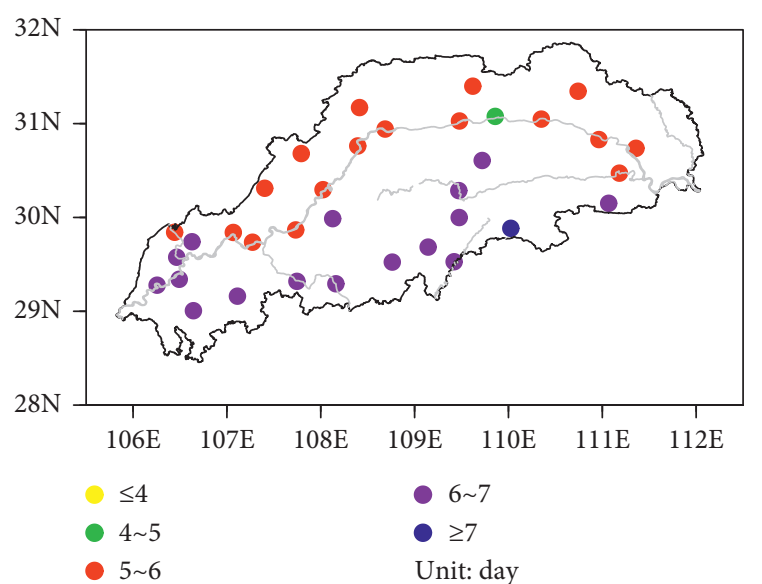

(a)

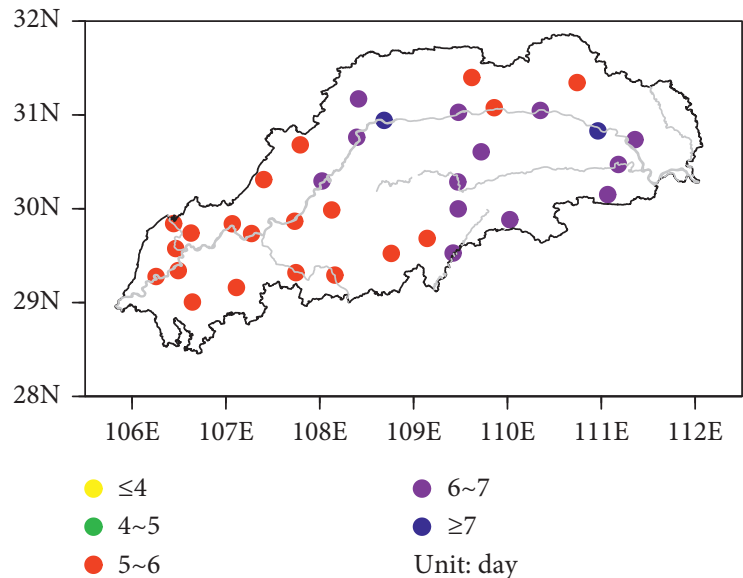

(c)

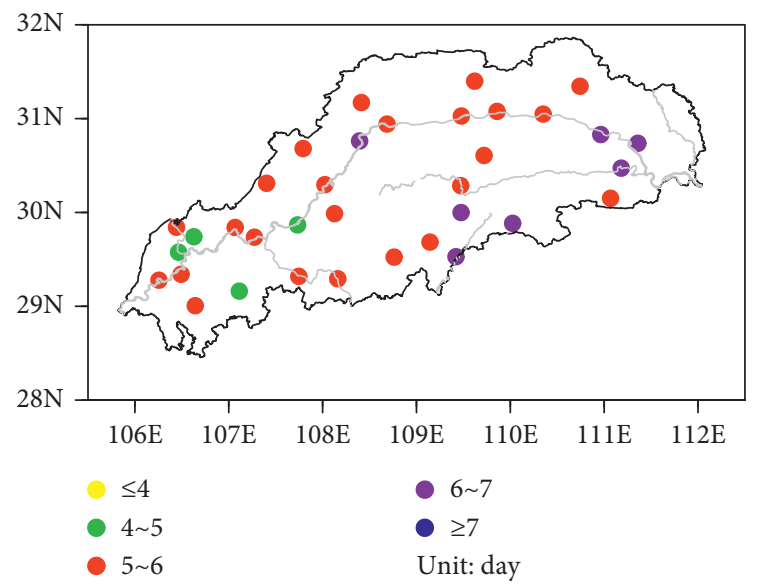

(b)

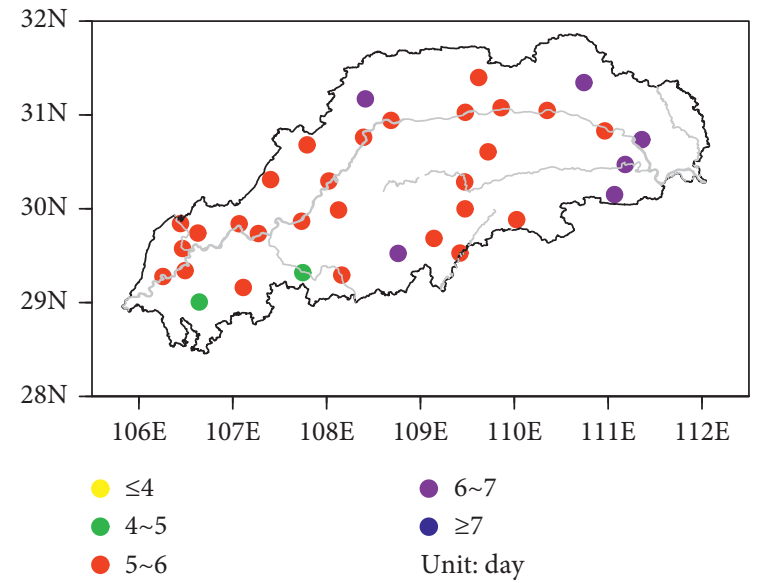

(d)

FIgURE 22: The spatial distribution of CWD calculated from (a) gauge observation, (b) TRMM, (c) CMORPH, and (d) PERSIANN at each rain-gauge station. 
Table 5: Maximum precipitation during the daytime, nighttime, and the whole day.

\begin{tabular}{lccc}
\hline & Daytime $(\mathrm{mm})$ & Nighttime $(\mathrm{mm})$ & Daily $(\mathrm{mm})$ \\
\hline TRMM & 54.06 & 54.20 & 75.44 \\
CMORPH & 42.30 & 61.33 & 71.17 \\
PERSIANN & 34.25 & 46.61 & 57.18 \\
\hline
\end{tabular}

\section{Conclusion}

The evaluation of three satellite products showed that both CMORPH and TRMM estimates were more accurate than the PERSIANN over the Three Gorges Reservoir area. In general, both CMORPH and TRMM showed a good performance in estimating the spatial pattern and temporal evolution of precipitation from subdaily to yearly timescales. The overall performance of CMORPH was slightly better than the TRMM. The PERSIANN tended to underestimate the rainfall amount at multiple timescales. All three satellite products could capture the main characteristic of the rainfall diurnal cycle, namely, more precipitation in the morning than in the evening. On the whole, the CMORPH errors were the least of all at daily and subdaily timescales (i.e., 3hourly and 12-hourly). The CMORPH estimates were better in the daytime than in nighttime. The performance of TRMM was generally close to the CMORPH. Both TRMM and CMORPH outperformed the PERSIANN on the monthly timescale and above. Note that the variation characteristics of satellite biases were different in four seasons. For example, the CMORPH underestimated the morning rainfall but overestimated the evening rainfall in summer and winter. This bias pattern was almost reversed in spring and autumn. In contrast, the bias pattern of TRMM remained the same in four seasons, which was the overestimation of rainfall in the morning and underestimation of rainfall in the evening. The bias amplitude of CMORPH was smaller in spring and autumn than in summer and winter whereas the bias amplitude of TRMM was smaller in summer and autumn than in spring and winter. In general, the CMORPH and TRMM were better at estimating the rainfall diurnal cycle than the PERSIANN over the Three Gorges Reservoir area.

The rainy-day detection ability of CMORPH was slightly better than the TRMM, and the latter was evidently better than the PERSIANN. Note that each satellite estimate had its own bias on the seasonal and yearly timescales. The bias of each satellite product was accumulated from the monthly timescale, in which the PERSIANN tended to overestimate the frequency of occurrence of light rain but underestimate that of the heavy rain and rainstorm. The CMORPH overestimated mainly the frequency of occurrence of moderate rain whereas the TRMM overestimated the frequency of occurrence of heavy rain in the winter half year.

All satellite estimates of extreme precipitation deviated from the observation to a varying degree. For the maximum 5-day precipitation, the CMORPH estimate was the most realistic of all satellite products. Both TRMM and CMORPH overestimated the 95th percentile of daily precipitation, which was severely underestimated by the PERSIANN. For the maximum persistent rainy days, the bias of TRMM was the least of all. Nevertheless, both TRMM and CMORPH had a larger bias than the PERSIANN for the average maximum precipitation on the subdaily timescales. It can be inferred from the above results that the key technologies used in the CMORPH, including the infrared measurements from the Geostationary Operational Environmental Satellites and the GEO-IR-based vector computation, are suitable for the rainfall estimation over the research area. The PERSIANN uses artificial neural networks to derive precipitation rate from the IR imagery of cloud-top temperature, which is unsuitable for estimating the precipitation over the Three Gorges Reservoir area.

The recent climate change is accompanied by distinct regional variations of precipitation around the world. At present, the satellite rainfall estimates still have discrepancies compared to the observation and other reanalysis datasets. Our results generally coincided with Li and Tang [37] and Zhou et al. [50], which only evaluated the TRMM data over the Three Gorges Reservoir area. The PERSIANN estimate showed comparatively poor performance not only over the reservoir area but also over other places including the Tibetan Plateau and the Taklamakan Desert [51], the coastal region of the Caspian Sea [52], the Middle East [53], and the arid region of Egypt [13]. The reason could be related to warmer cloud-top temperature and insufficient gauge-corrected records for calibration [54], but it still needs further investigation.

Previous studies suggested that the accuracy of TRMM and CMORPH products was affected by the topography $[55,56]$. For the Three Gorges Reservoir area, the complex terrain with altitude from $34 \mathrm{~m}$ to $2854 \mathrm{~m}$, the topographic effect could be the main reason for some rare but large biases of TRMM and CMORPH products. Besides, most parts of the reservoir area are dominated by cloudy and foggy weather, especially in winter. The foggy days in winter account for $41 \%$ of total foggy days for the whole year [57]. This makes the upper troposphere more prone to being shielded by continental clouds, and the low-level clouds with precipitation are hard to detect [58]. Thus, the regional cloudy weather could also be a reason for larger biases in winter than in other seasons.

Note that the estimate errors of each satellite are related to the climate background and the representation of the orographic effect in the inversion algorithm. The source of these errors needs to be clarified in future studies. On the other hand, the performance of satellite products can be improved using physical empirical model [59], incorporating the passive microwave precipitation data [60], and integrating artificial intelligence (AI) with autoregressive models and machine learning techniques (such as the genetic programming) $[61,62]$. As a growing trend of meteorological technology, the application and improvement of 
these AI-based bias correction technologies also deserved further investigation. This study could serve as a reference for data fusion of observed precipitation and satellite measurement over the Three Gorges Reservoir area and thus facilitated a more effective climate evaluation and a more accurate hydrological simulation.

\section{Data Availability}

The TRMM 3B42_V7 data were provided by Goddard Earth Sciences Data and Information Services Center (GES DISC) (available at https://disc2.gesdisc.eosdis.nasa.gov/data/ TRMM_L3/TRMM_3B43.7). The PERSIANN-CDR data were provided by NOAA National Centers for Environmental Information (available at https://catalog.data.gov/dataset/ noaa-climate-data-record-cdr-of-precipitation-estimationfrom-remotely-sensed-information-using). The CMORPH_CRT data were provided by the Climate Prediction Center (CPC) of the National Oceanic and Atmospheric Administration (NOAA) (available at https://www.cpc.ncep. noaa.gov/products/janowiak/cmorph_description.html).

\section{Conflicts of Interest}

The authors declare that there are no conflicts of interest regarding the publication of this paper.

\section{Authors' Contributions}

Tianyu Zhang and Yu Yang, Zeyu Dong contributed equally to this study.

\section{Acknowledgments}

This work was supported by the National Natural Science Foundation of China (42022035, 42030603, 41861144012, 41875103, 41975093, 42005050, 41805059, 41875111, and 40975058), the Strategic Priority Research Program of Chinese Academy of Sciences (XDB40000000), the Natural Science Foundation of Yunnan Province (2019FY003006), and the Program for Provincial Innovative Team of the Climate Change Study of Greater Mekong Subregion (2019HC027). It was also cosupported by Yunnan Science and Technology Department Youth Project (202001BB050014), the Three Gorges Climate Monitoring Project of China (sk2021015), the National Key R\&D Projects of China (2018YFE0196000), and the Climate Change Project of China Meteorological Administration of China (CCSF-201836).

\section{References}

[1] Y. Liu, Q. Fu, P. Song, X. Zhao, and C. Dou, "Satellite retrieval of precipitation: an overview," Advances in Earth Science, vol. 26, pp. 1162-1172, 2011, in Chinese.

[2] P. C. Qin, H. M. Xu, M. Liu et al., "Climate change impacts on three Gorges reservoir impoundment and hydropower generation," Journal of Hydrology, vol. 580, no. 13, 2020.

[3] Y. X. Zeng, Z. X. Zhou, Z. G. Yan, M. J. Teng, and C. B. Huang, "Climate change and its attribution in three Gorges reservoir area, China," Sustainability, vol. 11, p. 20, 2019.
[4] G. J. Huffman, E. F. Stocker, D. T. Bolvin, E. J. Nelkin, and R. F. Adler, TRMM Version $73 B 42$ and 3B43 Data Sets, NASA/GSFC, Greenbelt, MD, USA, 2012.

[5] R. J. Joyce, J. E. Janowiak, P. A. Arkin, and P. Xie, "CMORPH: a method that produces global precipitation estimates from passive microwave and infrared data at high spatial and temporal resolution," Journal of Hydrometeorology, vol. 5, no. 3, pp. 487-503, 2004.

[6] H. Ashouri, K.-L. Hsu, S. Sorooshian et al., "PERSIANNCDR: daily precipitation climate data record from multisatellite observations for hydrological and climate studies," Bulletin of the American Meteorological Society, vol. 96, no. 1, pp. 69-83, 2015.

[7] K. i. Okamoto, T. Ushio, T. Iguchi, N. Takahashi, and K. Iwanami, "The global satellite mapping of precipitation (GSMaP) project," in Proceedings of the 2005 IEEE International Geoscience and Remote Sensing Symposium, 2005 (IGARSS '05), vol. 5, Seoul, South Korea, July 2005.

[8] R. Guo and Y. Liu, "Multi-satellite retrieval of high resolution precipitation: an overview," Advance in Earth Sciences, vol. 30, pp. 891-903, 2015.

[9] S. Zhang, D. Wang, Z. Qin, Y. Zheng, and J. Guo, "Assessment of the GPM and TRMM precipitation products using the rain gauge network over the Tibetan plateau," Journal of Meteorological Research, vol. 32, no. 2, pp. 324-336, 2018.

[10] J. P. Kim, I. W. Jung, K. W. Park, S. K. Yoon, and D. Lee, "Hydrological utility and uncertainty of multi-satellite precipitation products in the mountainous region of South Korea," Remote Sensing, vol. 8, 2016.

[11] J. Ringard, M. Becker, F. Seyler, and L. Linguet, "Temporal and spatial assessment of four satellite rainfall estimates over French guiana and north Brazil," Remote Sensing, vol. 7, no. 12, pp. 16441-16459, 2015.

[12] A. Mondal, V. Lakshmi, and H. Hashemi, "Intercomparison of trend analysis of multisatellite monthly precipitation products and gauge measurements for river basins of India," Journal of Hydrology, vol. 565, pp. 779-790, 2018.

[13] M. S. Nashwan, S. Shahid, A. Dewan, T. Ismail, and N. Alias, "Performance of five high resolution satellite-based precipitation products in arid region of Egypt: an evaluation," Atmospheric Research, vol. 236, Article ID 104809, 2020.

[14] N. A. B. Klutse, K. A. Quagraine, F. Nkrumah et al., "The climatic analysis of summer monsoon extreme precipitation events over West africa in CMIP6 simulations," Earth Systems and Environment, vol. 5, no. 1, pp. 25-41, 2021.

[15] M. S. Nashwan and S. Shahid, "Spatial distribution of unidirectional trends in climate and weather extremes in Nile river basin," Theoretical and Applied Climatology, vol. 137, no. 1-2, pp. 1181-1199, 2019.

[16] A. Y. M. Abdullah, M. H. Bhuian, G. Kiselev, A. Dewan, Q. K. Hasan, and M. Rafiuddin, "Extreme temperature and rainfall events in Bangladesh: a comparison between coastal and inland areas," International Journal of Climatology, 2020.

[17] Y. Shen, A. Xiong, Y. Wang, and P. Xie, "Performance of highresolution satellite precipitation products over China," Journal of Geophysical Research: Atmospheres, vol. 115, 2010.

[18] L. Cheng, R. Shen, C. Shi, L. Bai, and Y. Yang, "Evaluation and verification of CMORPH and TRMM 3B42 precipitation estimation products," Meteorological Monthly, vol. 40, pp. 1372-1379, 2014.

[19] R. Liao, D. Zhang, and Y. Shen, "Validation of six satellitederived rainfall estimates over China," Meteorological Monthly, vol. 41, pp. 970-979, 2015. 
[20] L. Zhu, Y. Zhao, X. Rui, and Q. Wei, "Diurnal variation of seasonal precipitation over the CONUS: a comparison of gauge observations with TRMM data," Advances in Meteorology, vol. 2020, Article ID 8859993, 13 pages, 2020.

[21] G. Chen, R. Lan, W. Zeng, H. Pan, and W. Li, "Diurnal variations of rainfall in surface and satellite observations at the monsoon coast (South China)," Journal of Climate, vol. 31, no. 5, pp. 1703-1724, 2018.

[22] J. Guo, P. Zhai, L. Wu et al., "Diurnal variation and the influential factors of precipitation from surface and satellite measurements in Tibet," International Journal of Climatology, vol. 34, no. 9, pp. 2940-2956, 2014.

[23] L. Wu and P. Zhai, "Validation of daily precipitation from two high-resolution satellite precipitation datasets over the Tibetan Plateau and the regions to its east," Acta Meteorologica Sinica, vol. 26, no. 6, pp. 735-745, 2012.

[24] M. Zhang, A. Huang, X. Ji, M. Wang, and Y. Tan, "Validation of satellite precipitation products over qinghai-xizang plateau region," Plateau Meteorology, vol. 35, pp. 34-42, 2016.

[25] Q. Hu, D. Yang, Y. Wang, and H. Yang, "Accuracy and spatiotemporal variation of high resolution satellite rainfall estimate over the Ganjiang river basin," Science China Technological Sciences, vol. 56, no. 4, pp. 853-865, 2013.

[26] S. Jiang, Z. Zhang, Y. Huang, X. Chen, and S. Chen, "Evaluating the TRMM multisatellite precipitation analysis for extreme precipitation and streamflow in ganjiang river basin, China," Advances in Meteorology, vol. 2017, Article ID 2902493, 11 pages, 2017.

[27] X. Yang and W. Geng, "Accuracy evaluation of TRMM-based multi-satellite precipitation in huai river basin," Water Resources and Power, vol. 34, pp. 1-5, 2016, in Chinese.

[28] J. Wang, H.-J. Wang, and Y. Hong, "Comparison of satelliteestimated and model-forecasted rainfall data during a deadly debris-flow event in Zhouqu, Northwest China," Atmospheric and Oceanic Science Letters, vol. 9, no. 2, pp. 139-145, 2016.

[29] Y. Yang, G. Cheng, J. Fan, J. Sun, and W. Li, "Accuracy validation of TRMM 3B42 data in Sichuan basin and the surrounding areas," Journal of the Meteorological Sciences, vol. 33, pp. 526-535, 2013.

[30] Q. Jiang, W. Li, J. Wen et al., “Accuracy evaluation of two high-resolution satellite-based rainfall products: TRMM 3B42V7 and CMORPH in Shanghai," Water, vol. 10, 2018.

[31] Z. Li, D. Yang, and Y. Hong, "Multi-scale evaluation of highresolution multi-sensor blended global precipitation products over the Yangtze river," Journal of Hydrology, vol. 500, pp. 157-169, 2013.

[32] T. Ji, R. Liu, H. Yang, T. He, and J. Wu, "Spatial downscaling of precipitation using multi-source remote sensing data: a case study of sichuan-chongqing region," Journal of Geo-Information Science, vol. 17, pp. 108-117, 2015.

[33] T. Ji, H. Yang, R. Liu, T. He, and J. Wu, "Applicability analysis of the TRMM precipitation data in the SichuanChongqing region," Progress in Geography, vol. 33, pp. 1375-1386, 2014.

[34] J. Wu, A. Chen, T. Ji, C. Zhu, and X. Lu, "Resources,Environment and ecology in three Gorges area the applicability analysis of TRMM precipitation in the three Gorges reservoir area of chongqing and its spatial-temporal distribution," Journal of Chongqing Normal University, vol. 31, pp. 70-77, 2014.

[35] W. Wang, W. Zhang, W. Tan, and X. Wu, "Applicability analysis of TRMM3B43 precipitation product concerning the spatial and temporal heterogeneity of precipitation:taking Hubei Province as an example," Geography and Geo-Information Science, vol. 33, pp. 59-66, 2017.
[36] P. Bai and X. Liu, "Evaluation of five satellite-based precipitation products in two gauge-scarce basins on the Tibetan plateau," Remote Sensing, vol. 10, 2018.

[37] B. Li and S. Tang, "Local precipitation changes induced by the three gorges reservoir based on TRMM observations," Resources and Environment in the Yangtze Basin, vol. 23, pp. 617-625, 2014.

[38] H. V. Gupta, H. Kling, K. K. Yilmaz, and G. F. Martinez, "Decomposition of the mean squared error and NSE performance criteria: implications for improving hydrological modelling," Journal of Hydrology, vol. 377, no. 1-2, pp. 80-91, 2009.

[39] H. Kling, M. Fuchs, and M. Paulin, "Runoff conditions in the upper Danube basin under an ensemble of climate change scenarios," Journal of Hydrology, vol. 424-425, pp. 264-277, 2012.

[40] F. Bliemel, "Theil's forecast accuracy coefficient: a clarification," Journal of Marketing Research, vol. 10, no. 4, pp. 444-446, 1973.

[41] R. Z. Li, A. D. Zhang, H. Zhang, and D. J. Jiang, "Accuracy evaluation of multi-satellite precipitation products over Circum-Bohai-Sea Region," Ying Yong Sheng Tai Xue Bao = The Journal of Applied Ecology, vol. 27, pp. 2916-2924, 2016.

[42] E. E. Ebert, "Methods for verifying satellite precipitation estimates," in Measuring Precipitation from Space. Advances In Global Change Research, V. Levizzani, P. Bauer, and F. J. Turk, Eds., Vol. 28, Springer, Dordrecht, Netherlands, 2007.

[43] K. K. Rao, S. K. Patwardhan, A. Kulkarni, K. Kamala, S. S. Sabade, and K. K. Kumar, "Projected changes in mean and extreme precipitation indices over India using PRECIS," Global and Planetary Change, vol. 113, pp. 77-90, 2014.

[44] Z. Ren, M. Zhang, S. Wang, X. Zhu, L. Dong, and F. Qiang, "Changes in precipitation extremes in South China during 1961-2011,” Acta Geographica Sinica, vol. 69, pp. 640-649, 2014.

[45] D. Chen, T. Ou, L. Gong et al., "Spatial interpolation of daily precipitation in China: 1951-2005," Advances in Atmospheric Sciences, vol. 27, no. 6, pp. 1221-1232, 2010.

[46] F. Jalili Pirani and R. Modarres, "Geostatistical and deterministic methods for rainfall interpolation in the Zayandeh Rud basin, Iran," Hydrological Sciences Journal, vol. 65, no. 16, pp. 2678-2692, 2020.

[47] M. Lu, Y. Jiang, X. Chen, J. Chen, S. Wu, and J. Liu, "Spatiotemporal variations of extreme precipitation under a changing climate in the three Gorges reservoir area (TGRA)," Atmosphere, vol. 9, 2018.

[48] Y. Zhang, J. Sun, and S. Fu, "Impacts of diurnal variation of mountain-plain solenoid circulations on precipitation and vortices east of the Tibetan Plateau during the Mei-Yu season," Advances in Atmospheric Sciences, vol. 31, no. 1, pp. 139-153, 2014.

[49] X. Liu, Q. Yang, R. Wang, and B. Cheng, "Variation characteristics of water vapor resources over the three Gorges reservoir area during 1980-2009," Journal of Natural Resources, vol. 27, pp. 1550-1560, 2012.

[50] L. Zhou, H. Yang, R. Liu et al., "Spatial-temporal characteristics of annual precipitation in Southwest China based on TRMM 3B43 V7 data," Journal of Chongqing Normal University (Natural Science Edition), vol. 34, pp. 114-122, 2017, in Chinese.

[51] C. Miao, H. Ashouri, K.-L. Hsu, S. Sorooshian, and Q. Duan, "Evaluation of the PERSIANN-CDR daily rainfall estimates in capturing the behavior of extreme precipitation events over 
China," Journal of Hydrometeorology, vol. 16, no. 3, pp. 1387-1396, 2015.

[52] M. Alijanian, G. R. Rakhshandehroo, A. K. Mishra, and M. Dehghani, "Evaluation of satellite rainfall climatology using CMORPH, PERSIANN-CDR, PERSIANN, TRMM, MSWEP over Iran," International Journal of Climatology, vol. 37, no. 14, pp. 4896-4914, 2017.

[53] A. M. El Kenawy, M. F. McCabe, J. I. Lopez-Moreno et al., "Spatial assessment of the performance of multiple highresolution satellite-based precipitation data sets over the Middle East," International Journal of Climatology, vol. 39, no. 5, pp. 2522-2543, 2019.

[54] C. Kidd and G. Huffman, "Global precipitation measurement," Meteorological Applications, vol. 18, no. 3, pp. 334-353, 2011.

[55] A. Bai, X. Liu, and C. Liu, "Contrast of diurnal variations of summer precipitation between the Tibetan Plateau and Sichuan Basin," Plateau Meteorology, vol. 30, pp. 852-859, 2011, in Chinese.

[56] Y. Fu, G. Liu, G. Wu et al., "Tower mast of precipitation over the central Tibetan Plateau summer," Geophysical Research Letters, vol. 33, 2006.

[57] T. Y. Zhang, J. Sun, and Y. Wang, "Impact of climate change on fog days in Chongqing," Journal of Southwest University for Nationalities (Natural Science Edition), vol. 36, pp. 126-134, 2014, in Chinese.

[58] J. Liu, R. Chen, C. Han, and C. Tan, "Evaluating TRMM multisatellite precipitation analysis using gauge precipitation and MODIS snow-cover products," Applied Water Science, vol. 21, pp. 343-348, 2010.

[59] G. F. Ziarh, S. Shahid, T. B. Ismail, M. Asaduzzaman, and A. Dewan, "Correcting bias of satellite rainfall data using physical empirical model," Atmospheric Research, vol. 251, p. 105430, 2021.

[60] N. Karbalaee, K. Hsu, S. Sorooshian, and D. Braithwaite, "Bias adjustment of infrared-based rainfall estimation using passive microwave satellite rainfall data," Journal of Geophysical Research: Atmospheres, vol. 122, no. 7, pp. 3859-3876, 2017.

[61] N. Nasrollahi, K. Hsu, and S. Sorooshian, "An artificial neural network model to reduce false alarms in satellite precipitation products using MODIS and CloudSat observations," Journal of Hydrometeorology, vol. 14, no. 6, pp. 1872-1883, 2013.

[62] Y. Tao, X. Gao, A. Ihler, S. Sorooshian, and K. Hsu, "Precipitation identification with bispectral satellite information using deep learning approaches," Journal of Hydrometeorology, vol. 18, no. 5, pp. 1271-1283, 2017. 